\title{
LA PROTECCIÓN DE LA LENGUA CASTELLANA EN EL MARCO DEL MULTIPARLAMENTARISMO AUTONÓMICO: EL ACCESO A LA INFORMACIÓN PÚBLICA EN ESPAÑOL EN LA WEB OFICIAL DE LOS PARLAMENTOS AUTONÓMICOS
}

AINHOA URIBE OTALORA 
SUMARIO

I. INTRODUCCIÓN: PLANTEAMIENTO DEL OBJETO DE ESTUDIO. II. PLANTEAMIENTO JURÍDICO DE LA CUESTIÓN. 2.1. EL ARTÍCULO 3 DE LA CONSTITUCIÓN: ANTECEDENTES Y SIGNIFICADO. 2.2. LOS PRINCIPIOS CONSTITUCIONALES DEL BILINGÜISMO. 2.3. EL MARCO JURÍDICO AUTONÓMICO DEL BILINGÜISMO. 2.4. LA JURISPRUDENCIA SOBRE LA LENGUA CASTELLANA. 2.5. EL DERECHO A CONOCER LAS LEYES Y ACCEDER A LA INFORMACIÓN PÚBLICA EN LENGUA CASTELLANA. III. LA PRAXIS DEL MULTIPARLAMENTARISMO EN EL CUMPLIMIENTO DEL ARTÍCULO 3 CE, 9CE Y ARTÍCULO 12 DE LA LEY DE TRANSPARENCIA. IV. CONCLUSIONES. VI. BIBLIOGRAFÍA. 


\title{
LA PROTECCIÓN DE LA LENGUA CASTELLANA EN EL MARCO DEL MULTIPARLAMENTARISMO AUTONÓMICO: EL ACCESO A LA INFORMACIÓN PÚBLICA EN ESPAÑOL EN LA WEB OFICIAL DE LOS PARLAMENTOS AUTONÓMICOS
}

\author{
AINHOA URIBE OTALORA ${ }^{1}$ \\ Profesora Titular en Ciencia Política. Universidad CEU San Pablo
}

\section{INTRODUCCIÓN: PLANTEAMIENTO DEL OBJETO DE ESTUDIO}

El objetivo del artículo es analizar la protección del español como lengua oficial en el marco del multiparlamentarismo autonómico. El artículo 3 de la Constitución Española (CE) establece que el castellano ${ }^{2}$ es la lengua oficial del Estado, al tiempo que reconoce la existencia de un plurilingüismo, puesto que las demás lenguas españolas serán también oficiales en sus respectivas Comunidades Autónomas, de acuerdo con sus Estatutos. Sin embargo, existen territorios donde los ciudadanos se enfrentan a una situación desigual a la hora de emplear el castellano como lengua vehicular.

El estudio empírico analizará el cumplimiento del artículo 3 CE, en relación con el artículo 9 CE (sobre la obligatoria publicación de las normas) y con el artículo 12 de la Ley 19/2013, de 9 de diciembre, de Transparencia, Acceso a la Información

${ }^{1}$ Profesora Titular en Ciencia Política. Universidad CEU San Pablo. Facultad de Derecho. Avenida del Valle 21. 28003 Madrid. Email: ainhoa.uribeotalora@ceu.es

${ }^{2}$ Al hablar de español, debe atenderse la sugerencia de la Real Academia de la Lengua Española sobre la sinonimia entre «español» y «castellano», de modo que no cabría suponer que el castellano es patrimonio de una única región, Castilla, sino que todas las regiones y nacionalidades habidas en España colaboran en la conservación y enriquecimiento de la lengua castellana o española. 
Pública y Buen Gobierno ${ }^{3}$, que amplía y refuerza las obligaciones de publicidad activa y pasiva, poniendo a disposición de los ciudadanos información institucional, organizativa y de planificación. Dicha publicidad implica que la información y/o normativa de acceso al ciudadano lo sea tanto en lengua castellana como en la lengua cooficial respectiva.

La novedad y oportunidad de la investigación, radica en que, pese a que hay mucho escrito sobre el bilingüismo, aquí se persigue relacionar esta cuestión con el cumplimiento efectivo del artículo $3 \mathrm{CE}$ de forma empírica, contrastando el mandato constitucional con el artículo 9CE y la Ley de Transparencia, para valorar qué información pública ofrecen, en la praxis, los parlamentos autonómicos (con lengua cooficial) en castellano ${ }^{4}$ a través de sus webs. El objetivo último es abordar unas conclusiones que permitan fortalecer y hacer cumplir el mandato constitucional, partiendo de la premisa básica de que no son las lenguas quienes disfrutan de derechos, sino que, como recuerda Francisco Rubio Llorente ${ }^{5}$, «la cooficialidad obliga al poder, pero es para los ciudadanos un puro derecho», porque parafraseando a Roberto L. Blanco Valdés ${ }^{6}$, «son las personas las que tienen derechos lingüísticos derivados de la Constitución».

\section{PLANTEAMIENTO JURÍDICO DE LA CUESTIÓN}

\subsection{El artículo 3 de la Constitución: antecedentes y significado}

La Constitución española reconoce por primera vez en nuestra historia constitucional la pluralidad lingüística, en el artículo $3 \mathrm{CE}$. Desde la óptica del Derecho Comparado, podemos encontrar algunos precedentes históricos sobre los derechos de las minorías lingüísticas. Rafael Entrena Cuesta ${ }^{7}$ destaca como ejemplos del reconocimiento jurídico del bilingüismo el artículo 6 de la Constitución italiana de 1947, que remite a la tutela de las minorías lingüísticas por parte de la República con

\footnotetext{
2017.

Vid. https:/www.boe.es/boe/dias/2013/12/10/pdfs/BOE-A-2013-12887.pdf Fecha: 4 febrero

${ }^{4}$ Una primera versión del artículo se presentó en una comunicación en el Congreso de la Asociación de Constitucionalistas de España (ACE), celebrado en la Universidad de León, en marzo de 2017. El análisis de los datos estadísticos de las webs parlamentarias data de la enero-marzo de 2017.

5 RUBIO LLORENTE, Francisco, «La Ley de Política Lingüística de la Generalitat Catalana», Cuadernos de Alzate: revista vasca de la cultura y las ideas, n. . 20, 1999, págs. 52-64 (p. 58).

${ }^{6}$ BLANCO VALDÉS, Roberto L. «Políticas lingüísticas y construcción nacional: El laboratorio español», en Anuario de la Facultad de Derecho de la Universidad Autónoma de Madrid, n. ${ }^{\circ}$. 17, 2013, pp. 475-500 (p. 494).

Véase ENTRENA CUESTA, Rafael, «Artículo 3», en GARRIDO FALLA, Fernando, Comentarios a la Constitución, Civitas, Madrid, 2004, pp. 71-79 (p. 71).
} 
normas especiales, y el artículo 59 bis de la Constitución belga de 1831, que crea consejos culturales para las comunidades lingüísticas.

La redacción actual del artículo 3CE encuentra su precedente histórico a nivel nacional en el artículo 4 de la Constitución de 1931. La Constitución de 1931, se refiere al castellano en varias disposiciones: el artículo 4 y el artículo 50. El artículo 4 establece que «el castellano es el idioma oficial de la República», por lo que «todo español tiene obligación de saberlo y derecho de usarlo, sin perjuicio de los derechos que las leyes del Estado reconozcan a las lenguas de las provincias o regiones». De modo que, «salvo lo que se disponga en leyes especiales, a nadie se le podrá exigir el conocimiento ni el uso de ninguna lengua regional» ${ }^{8}$. La Constitución de 1931 reconoce por primera vez el plurilingüismo, pero da primacía al castellano como lengua oficial. En materia educativa, por consiguiente, el artículo 50 dispone que las regiones autónomas pueden organizar la enseñanza en sus respectivas lenguas, siendo «obligatorio el estudio de la lengua castellana (...) en todos los Centros de instrucción primaria y secundaria de las regiones autónomas». El desarrollo de esta competencia en el ámbito de educación por las regiones, supone que «el Estado ejercerá la suprema inspección en todo el territorio nacional».

No es la primera vez que hay una referencia jurídica al castellano, aunque sí será la primera que se normativice el plurilingüismo. Existen algunos precedentes jurídicos en España que hablan del castellano y que conviene mencionar brevemente. En efecto, dejando de lado las Partidas de Alfonso X el Sabio, podemos citar como antecedentes jurídicos en los que se menciona la lengua común de los españoles: la Ley Moyano de Instrucción Pública de 1857 (art. 68), la Ley de enjuiciamiento Civil de 1881 (art. 601), o el Código Civil de 1889 (art. 684).

Según Juan Ramón LODARES, «cuando las Cortes Constituyentes en 1931 se plantean oficializar el español por primera vez en nuestra bistoria (...) no lo bacen como un reconocimiento natural del valor común de dicha lengua, de su irradiación a lo largo de los siglos, de su peso económico o cultural, sino porque la oficialización se advierte como la única vía de atajar la segregación lingüística a la que, faltamente, van a conducir los proyectos estatutarios, sobre todo en Cataluña, donde ya se había becho oficial la lengua catalana»".

Durante el franquismo, también son constantes las referencias al idioma común, por ejemplo, en la Ley de Enseñanza Primaria de 1945, la Ley de Registro Civil de 1957 (art. 54), el Decreto 1433/1975 sobre incorporación de las lenguas nativas en los programas de enseñanza y el Decreto 2929/1975 sobre uso de las lenguas regionales; la Ley de Enjuiciamiento Civil de 1882 (art. 440) y la Ley de Educación de 1970 (art. 24). De hecho, Juan Ramón LODARES menciona que el propio Franco había hablado de la castellanización de España en un diario americano, señalando que: «el carácter de cada región será respetado, pero sin perjuicio para la unidad nacional, que la queremos absoluta, con una sola lengua, el castellano, y una sola personalidad, la española» ${ }^{10}$.

${ }^{8}$ Constitución de 1931, disponible en http://www.congreso.es/constitucion/ficheros/historicas/ cons_1931.pdf Fecha de consulta: 5 abril 2017.

9 LODARES, Juan Ramón, Lengua y Patria, Taurus, Madrid, 2001, p. 131.

10 Francisco Franco, tal y como se cita en Ibidem, p. 143. 
El anteproyecto Constitucional (BOC de 5 de enero de 1978) disponía que el castellano era la lengua oficial del Estado, teniendo todos los españoles el deber de conocerlo y el derecho a usarlo, siendo las demás lenguas de España también oficiales en las Comunidades Autónomas, de acuerdo con sus respectivos Estatutos. Esta riqueza lingüística debía ser objeto de especial respeto y protección. En contra de la constitucionalización del castellano como lengua oficial se manifestaron algunos diputados nacionalistas ${ }^{11}$.

Un problema inicial del debate constituyente fue de carácter terminológico, sobre el empleo del término lengua española o lengua castellana. En este punto primó el criterio de la Real Academia de la Lengua sobre la sinonimia entre el castellano y el español. La Real Academia de la Historia también se adhirió a ese criterio, al afirmar que el castellano no es patrimonio de Castilla, sino que ha sido creada por todos los españoles e hispanoamericanos. Estos argumentos fueron aplaudidos por el Grupo Parlamentario de Unión de Centro Democrático, aunque la redacción del artículo se modificó ligeramente ${ }^{12}$. La cuestión fue resuelta de forma paradójica, como recuerda Rafael Entrena al señalar que en la versión definitiva del artículo no se habla «del castellano simplemente, ni del castellano o español, sino que se llega al feliz descubrimiento de que el castellano es una lengua española» ${ }^{13}$. Sobre este punto, sin embargo, hay opiniones diferentes, Sánchez Agesta, por ejemplo, sostiene, por el contrario, que la Constitución acertó al referirse a la lengua de España como lengua castellana, y no española, ya que ello deja espacio a considerar también como españolas las demás lenguas cooficiales ${ }^{14}$.

Resuelta la cuestión terminológica el artículo 3 quedó redactado del siguiente modo:

1. «El castellano es la lengua oficial del Estado. Todos los españoles tienen el deber de conocerla y el derecho a usarla.

2. Las demás lenguas españolas serán también oficiales en las respectivas Comunidades Autónomas de acuerdo con sus Estatutos.

3. La riqueza de las distintas modalidades lingüisticas de España es un patrimonio cultural que será objeto de especial respeto y protección».

${ }_{11}$ Tal es el caso de los señores Letamendia (Diario de Sesiones del Congreso, número 66, de 12 de mayo de 1978), Aguirre (Diario de Sesiones del Congreso, 67, 16 de mayo 1978) y Aubet (Diario de Sesiones del Congreso 41, 22 agosto 1978)

${ }^{12}$ El texto original del Anteproyecto decía: «El castellano o español es la lengua oficial del Estado y común de los españoles, quienes tienen el deber de conocerla y el derecho a usarla». La redacción se transforma posteriormente del siguiente modo: «El castellano o español es la lengua oficial del Estado. Todos los españoles tiene el deber de conocerla y el derecho a usarla». Diario de Sesiones del Senado, número 41, de 22 de agosto de 1978.

13 ENTRENA CUESTA, Rafael, «Artículo 3», en GARRIDO FALLA, Fernando, Comentarios a la Constitución, Civitas, Madrid, 2004, pp. 71-79 (p. 73).

${ }^{14}$ Véase SÁNCHEZ AGESTA, Luís, «La Lengua», en Óscar ALZAGA (dir.). Revista de Derecho Privado. Comentarios a la Constitución española de 1978, Madrid, 1983, pp. 199 y ss. 
El artículo 3 dispone, en el apartado primero, que «el castellano es la lengua española oficial del Estado», por lo que «todos los españoles tienen el deber de conocerla y el de derecho a usarla». El deber constitucional de conocer la lengua oficial podría resultar redundante en países monolingües. Sin embargo, es una necesidad en el caso español. En palabras de Rubio Llorente, «la redundancia que afecta a la consagración del deber de conocer la lengua oficial cuando ésta es única, desaparece cuando, como en el caso de España, la lengua oficial del Estado no es la única lengua oficial existente en su seno. En esa situación, este deber (al que va anejo el derecho de utilizar esa lengua en todo el territorio nacional) entraña una consecuencia que no se deriva de la simple calidad de lengua oficial, puesto que esa calidad la poseen diversas lenguas: la de que esas otras lenguas que no es obligado conocer sólo pueden ser cooficiales, o dicho en otros términos, que la oficialidad de las restantes lenguas españolas en el ámbito de las respectivas Comunidades Autónomas no puede ser exclusiva y que, por lo tanto, también el castellano es en ella lengua oficial» ${ }^{15}$.

Para Rafael Entrena, esta proclamación del deber y el derecho de conocer el castellano comporta las siguientes precisiones:

- Primera. «El término Estado se utiliza en sentido amplio, por lo que no debe entenderse referido a su Administración y a las Cortes Generales y el Poder judicial, sino al Estado como comunidad que incorpora a todos los españoles y de cuyo aparato organizativo, desde esta perspectiva forman parte también las Comunidades Autónomas, las Provincias, los Municipios y cuantos entes públicos no extranjeros existan en el territorio español» ${ }^{16}$.

- Segunda. La consagración constitucional del deber de conocer la lengua es consecuencia ineludible del carácter oficial de la lengua.

- Tercera. "El derecho a usarlo que se reconoce a todos los españoles se proyecta en todas las relaciones que pueda mantener con cualesquiera organismos y autoridades del Estado» ${ }^{17}$.

Francisco Rubio Llorente define el deber de conocer el castellano como un «deber en interés de la cohesión nacional» ${ }^{18}$. Sin embargo, lamenta que en los debates constituyentes "ninguno de los que en ella intervinieron intentó precisar qué relación existe entre oficialidad y deber de conocimiento de la lengua, qué es lo que, en su caso, añade a la oficialidad del castellano la consagración constitucional del deber de conocerlo y qué significado tiene, si tiene alguno, que se niegue la existencia de este deber respecto de las lenguas no castellanas» ${ }^{19}$. Los debates constituyentes no fueron todo lo profusos que

15 RUBIO LLORENTE, Francisco, op.cit., p. 50.

16 ENTRENA CUESTA, Rafael, op.cit., 2004, pp. 73.

17 Ibidem

${ }_{18}$ RUBIO LLORENTE, Francisco, «Los deberes Constitucionales», Revista Española de Derecho Constitucional, Año 21. Núm. 62. Mayo-Agosto 2001, pp. 11-56 (p. 48).

19 Ibidem, p. 49. 
debieran haber sido en una materia tan transcendental como la consideración del deber de conocer la lengua oficial ${ }^{20}$.

Por otro lado, en cuanto a la pluralidad lingüística de España, su protección y reconocimiento se elevan al rango constitucional ${ }^{21}$, mediante la afirmación de que «las demás lenguas españolas serán también oficiales en sus respectivas Comunidades Autónomas de acuerdo con sus Estatutos». Por consiguiente, el apartado tercero exige el respeto y protección de las «distintas modalidades lingüísticas de España», en tanto en cuanto son parte de su patrimonio cultural. Eliseo Aja afirma, al respecto que, «todos los movimientos democráticos, y no sólo los núcleos nacionalistas, que entonces eran muy reducidos, de los territorios que tenían una lengua propia convierten su defensa en factor de la lucha politica por la recuperación de la democracia y de la autonomía. No es extraño, pues, que la Constitución recogiera el reconocimiento y defensa de las diferentes lenguas que se hablan en España como elemento fundamental del nuevo sistema autonómico» ${ }^{22}$.

Esto es, aunque en la Constitución de la República aparece un reconocimiento de las lenguas regionales, la Constitución de 1978 ha ido más allá en el mismo, al afirmar en que todas las modalidades lingüísticas existentes en España son un patrimonio cultural de especial respeto y protección. Dicha especial protección que se confiere a las minorías lingüísticas aparece también en buena parte del ordenamiento jurídico internacional, como el artículo 27 del Pacto de Derechos Civiles y Políticos, que reconoce a las minorías lingüísticas el derecho a tener su propia vida cultural y a emplear su propio idioma, o en la Carta Europea de las Lenguas Regionales o Minoritarias de 1992, también ratificada por España (BOE núm. 222, 15 septiembre 2001).

En España se ha prestado tradicionalmente más importancia al apartado segundo que al primero y al tercero; si bien, en el tercero encontramos la declaración más amplia sobre los efectos del artículo 3 CE. Del citado precepto se deduce que España es un país con una realidad lingüística plural, pero además de ello, la palabra «riqueza» se refiere al conjunto de las modalidades lingüísticas del país, es decir, tanto al castellano, como al catalán, al vasco, al gallego, al valenciano, al aranés, al bable, al fragatino o al panocho. Hablar de riqueza, en este sentido, significa entender la realidad lingüística española,

${ }^{20}$ Los representantes del Grupo Vasco (Aguirre Querexeta en el Congreso y Monreal Zía en el Senado), afirmaron que el deber de conocimiento está ya implícito en la proclamación del castellano y pidieron la supresión del párrafo, por redundante. Se rechazaron las enmiendas que proponían incluir en la Constitución también el deber de conocer las lenguas oficiales no castellanas (así la enmienda 105, de Minoría Catalana, defendida en el Congreso por el Sr. Trías Farga, o la 697, del Grupo Comunista, defendida por el Sr. Solé Tura), pero también aquellas otras que, como la del Sr. de la Fuente en el Congreso, o las de los Sres. Gamboa Sánchez Barcáiztegui y Azcárate, en el Senado, pretendían que se negara expresamente la existencia de ese deber, o se dejase la cuestión a lo que dispongan leyes especiales, en la fórmula más suave del Sr. Azcárate, que retomó el texto del artículo 4.» de la Constitución de la Segunda República. Vid.Ibidem, p. 49.

21 Véase GURRERA ROIG, Matilde, «El pluralismo lingüístico», Revista de Estudios Políticos, núm. 48, noviembre-diciembre 1985, pp. 221-232 (pp. 228-231).

22 AJA, Eliseo, El Estado Autonómico. Federalismo y Hechos Diferenciales, Alianza Editorial, Madrid, 2007 , p. 179. 
en primer lugar, desde una perspectiva positiva y, en segundo lugar, como un todo solidario en tanto que se trata de un patrimonio cultural común. Ello implica además, un corte radical con el pasado, con una España monolingüe (desde el punto de vista jurídico, pese a que la realidad lingüística fuera sumamente variada).

\subsection{Los principios constitucionales del bilingüismo}

Uno de los principios básicos que se ven afectados por el artículo 3 CE es la libertad de lengua. Toda intromisión y coerción externa en la libertad del ser humano para escoger la lengua en la que quiere expresarse es un atentado a la libertad humana. Por consiguiente, la libertad de lengua está directamente relacionada con el libre desarrollo de la personalidad. Así pues, la Constitución propugna como valor superior el principio de la libertad (art. $1 \mathrm{CE}$ ), al tiempo que todas las personas tienen reconocido su derecho a la libertad de expresión (art. 20.1 CE). En este sentido, que la Administración declare como oficial una lengua no coarta la libertad de las personas siempre y cuando sean las lenguas naturales de la población las lenguas elegidas como oficiales. De modo que declarar el status público de una lengua minoritaria puede ser compatible con la libertad de la lengua, siempre que no contradiga las exigencias básicas de la igualdad (art. $14 \mathrm{CE}$ ) y resulte razonable y proporcional, como ha admitido la jurisprudencia en diversas sentencias (STC 82, 83 y 84/1986, de 26 de julio).

Un segundo principio afectado por lo referido en el artículo 3 CE es el principio de igualdad, que aparece en los artículos 1.1, 14, 9.2 y 149.1.1 CE. El artículo 1.1 $\mathrm{CE}$ se refiere a la igualdad como valor constitucional, como «valor superior del ordenamiento jurídico», que impregna todo el ordenamiento. El artículo 14 CE proclama el derecho público subjetivo a la igualdad y la no discriminación. Mientras, el artículo 9.2 consagra las obligaciones de los poderes públicos con la finalidad de promover las condiciones para que la igualdad del individuo y de los grupos en que se integre sea real y efectiva. Al tiempo que el artículo 149.1.1 establece la competencia exclusiva del Estado en materias que supongan la regulación de las condiciones básicas que garanticen la igualdad de todos los españoles en el ejercicio de los derechos y en el cumplimiento de los deberes constitucionales. La visión general del principio de igualdad ante la ley y no discriminación se encuentra también en las grandes declaraciones internacionales de derechos ${ }^{23}$.

${ }^{23}$ Como la Declaración Universal de Derechos Humanos de 10 de diciembre de 1948 (artículos 1, 2 y 7); el Pacto Internacional de Derechos Civiles y Políticos de 19 de diciembre de 1966 (artículos 2.1. ${ }^{\circ}$ y 2. ${ }^{\circ}, 20.2$, 26 y 27); el Pacto Internacional de Derechos Económicos, Sociales y Culturales de 19 de diciembre de 1966 (artículos 2.2. ${ }^{\circ}$ y 3. ${ }^{\circ}$ ); la Convención de las Naciones Unidas sobre los Derechos del Niño de 20 de noviembre de 1959 (artículos 1 y 10); el Convenio Europeo para la Protección de los Derechos Humanos y de las Libertades Públicas de 4 de octubre de 1950 (artículo 17), y la Carta de los derechos fundamentales de la Unión Europea proclamada solemnemente en Niza el 7 de diciembre de 2000 (artículos 20, 21 y 23). 
Un tercer principio afectado por la lengua, sería el principio de integración. Prueba de ello es que la Constitución española reconoce la pluralidad de modalidades lingüísticas como patrimonio histórico común, así como garantiza, en su artículo 2 $\mathrm{CE}$, «el derecho a la autonomía de las nacionalidades y regiones que la integran y la solidaridad entre todas ellas». Otro ejemplo de integración es la referencia en el apartado 2, del artículo 3 a las demás lenguas existentes bajo el calificativo de «españolas», es decir, el castellano sería la lengua española, y junto a éste existen otras lenguas también españolas, reforzando por ello la idea de convivencia, de bilingüismo y no de confrontación. Otro ejemplo de dicha integración estaría en la exigencia del artículo 20.3 CE de que en el acceso a los medios de comunicación social del Estado o de cualquier otro ente público se respetará el pluralismo de la sociedad y de las diversas lenguas de España. Del mismo modo, la disposición final de la Constitución ordenaba la publicación de la misma en todas las lenguas de España (como se hizo en el BOE de 29 de diciembre de 1978, en versión balear, catalana, gallega, valenciana y vasca).

De los tres principios anteriores se deduce que se puede exigir un determinado comportamiento a los poderes públicos, en aras a garantizar dicha realidad multilingüe. Así lo ha advertido el Tribunal Constitucional, en su sentencia 337/1994, de 23 de diciembre, al disponer que el artículo 3.3 CE conlleva «el mandato de todos los poderes públicos, estatal y autonómico, de fomentar el conocimiento y asegurar la protección de ambas lenguas en el territorio de la Comunidad». Esto es, todos los entes públicos (el Estado, las CCAA, las corporaciones locales y otros) tienen que respetar la riqueza cultural y lingüística española, lo que implica velar por la garantía de la oficialidad del castellano y de las demás lenguas cooficiales. De modo que la protección del castellano no es competencia exclusiva del Estado y la de las lenguas autonómicas de sus respectivas Comunidades Autónomas, sino que todos los entes públicos son responsables de proteger y promover el bilingüismo, como dejan patente también los Estatutos de Autonomía de las CCAA. Con todo, en el caso del castellano, la Constitución proclama el deber que tienen todos los españoles de conocerlo y su derecho a usarlo (art. 3.1 CE), mientras que el desarrollo que tengan las demás lenguas oficiales dependerá de sus respectivas Comunidades Autónomas.

Un ejemplo de este deber de protección del bilingüismo lo encontramos en la Ley 39/2015, de 1 de octubre, del Procedimiento Administrativo Común de las Administraciones Públicas, cuyo artículo 15 incluye entre los derechos de los ciudadanos en sus relaciones con las Administraciones Públicas el de «utilizar las lenguas oficiales en el territorio de la Comunidad Autónoma» ${ }^{24}$. En los procedimientos

${ }^{24}$ Artículo 15. Lengua de los procedimientos.

1. La lengua de los procedimientos tramitados por la Administración General del Estado será el castellano. No obstante lo anterior, los interesados que se dirijan a los órganos de la Administración General del Estado con sede en el territorio de una Comunidad Autónoma podrán utilizar también la lengua que sea cooficial en ella. En este caso, el procedimiento se tramitará en la lengua elegida por el interesado. Si concurrieran varios interesados en el procedimiento, y existiera discrepancia en cuanto a la lengua, el procedimiento se tramitará en castellano, si bien los documentos o testimonios que requieran los interesados se expedirán en la lengua elegida por los mismos. 
tramitados por la Administración del Estado la lengua a utilizar será el castellano, aunque los ciudadanos podrán dirigirse a los órganos de la Administración del Estado con sede en el territorio de una Comunidad Autónoma en la lengua cooficial en ésta. Dicho precepto impone también la obligación de traducir los documentos dirigidos a los interesados que así lo soliciten. Esta situación, como señalan Eduardo García de Enterría y Tomás Ramón Fernández «plantea en el ámbito del procedimiento administrativo problemas importantes, que bay que abordar y resolver a partir del principio aqui dominante, de la efectividad de las garantías del ciudadano frente a la Administración y de la categórica proscripción de la indefensión contenida en el artículo 24 de la Constitución» ${ }^{25}$. Desde esta perspectiva, "no basta a efectos de eliminar la indefensión con la obligación que se impone de traducir los documentos dirigidos a los interesados que así lo soliciten expresamente. No son éstos solamente (...) los documentos que los interesados tienen derecho a conocer y manejar (...)» ${ }^{26}$. Hay que entender pues que, si un interesado lo solicita, «debe procederse a la traducción completa del expediente tramitado en una lengua cooficial (...), ya que así como todos los españoles tienen el deber de conocer el castellano, no existe constitucionalmente un deber análogo respecto a las demás lenguas oficiales» ${ }^{27}$.

Pese a ello, se produce la paradoja de que hay autonomías que consideran la definición de una lengua como un concepto modulable. Tal es el caso de la Generalitat Catalana, que publicó en 2004 un documento de trabajo sobre el conocimiento del catalán en la provisión de puestos de trabajo en el ámbito de la justicia, en el que se cita expresamente a Jaume Vernet Llobet, quien sostiene que la oficialidad de una lengua es modulable porque depende de que exista una declaración por parte de los poderes públicos al respecto, cosa que ocurriría con el español ${ }^{28}$, mientras que otras lenguas que han tenido una implantación en España históricamente, como el árabe, no son lenguas oficiales porque no lo habría querido el legislador. Así, parecería que todo depende del capricho del legislador y que no responde a una realidad histórica, cultural y sociológica.

¿Por qué se ha llegado a esta situación en España en la que las lenguas cooficiales han copado terreno al castellano, hasta el punto de que los castellano-hablantes ven

3. La Administración Pública instructora deberá traducir al castellano los documentos, expedientes o partes de los mismos que deban surtir efecto fuera del territorio de la Comunidad Autónoma y los documentos dirigidos a los interesados que así lo soliciten expresamente. Si debieran surtir efectos en el territorio de una Comunidad Autónoma donde sea cooficial esa misma lengua distinta del castellano, no será precisa su traducción.

${ }^{25}$ GARCÍA DE ENTERRÍA, Eduardo y Tomás RAMÓN FERNÁNDEZ, Curso de Derecho Administrativo II, Thomson-Civitas, Madrid, 2006, pp. 522-523.

26 Ibidem, p. 523.

${ }^{27}$ Ibidem, p. 523.

28 VERNET LLOBET, Jaume (coord.), Dret lingüístic, Ed. Cossetània, Barcelona, 2003, p. 38, tal como se cita en PLA BOIX, Anna, «La valoració del coneixement de la llengua pròpia i del dret propi de Catalunya en la provisió de places del personal al servei de l'Administració de justicia», Centro de Estudios Jurídicos, Generalitat Catalana, 2004, p.7 en http://justicia.gencat.cat/web/.content/ documents/arxius/doc_59956114_1.pdf Fecha de consulta: 6 febrero 2017. 
cercenados sus derechos lingüísticos en algunas regiones? Roberto L. Blanco Valdés ${ }^{29}$ habla de tres posibles causas: La primera, el impulso normativo autonómico, cuya producción vulnera manifiestamente el proyecto bilingüista, (como se verá en el siguiente apartado); la segunda, lo que llama «decisiones sectoriales», esto es, formas de procedimiento interno adoptadas desde distintas instancias autonómicas (universidades, ayuntamientos, escuelas, etc.) que han hecho prevalecer la lengua cooficial. Blanco pone el ejemplo de que el castellano no existe en ninguna de las tres universidades gallegas, pese a que sea ésta una lengua de uso habitual entre sus estudiantes; y la tercera causa estaría relacionada con «una determinada forma de entender la corrección política lingüística en los territorios plurilingües». Esta corrección remite al uso habitual de la lengua, ya que los ciudadanos parecen haber interiorizado que, en público, hay que utilizar la lengua cooficial, ya que el uso del castellano se asocia a valores negativos. Ello ha generado el efecto perverso de que se ha utilizado «la política lingüística no como palanca de imposición institucional sino como instrumento de ingeniería social». Es decir, se ha euskaldunizado donde no había vasco-parlantes, se ha catalanizado donde no había catalano-parlantes, y así sucesivamente en el resto de los territorios.

Otra posible explicación sería que la ofrece Rubio Llorente respecto a la falta de consideración y reconocimiento en la sociedad y las propias instituciones del deber constitucional del conocimiento del castellano. En su opinión, hay «una notable muestra de esta tendencia a olvidar la existencia del deber constitucional de conocer el castellano, y en consecuencia a considerar ese conocimiento como un simple dato de becho, lo que inevitablemente lleva a equiparar ese conocimiento con el de cualquiera otra lengua española, es el que ofrecen las normas que regulan la adquisición de la nacionalidad, todas ellas posteriores a la Constitución. El Código Civil, modificado en este punto por la Ley 18/1990, de 17 de diciembre, no incluye el conocimiento del castellano, ni directa ni indirectamente, entre las condiciones necesarias para tal adquisición» ${ }^{30}$. Éste sería uno de tantos ejemplos en los que la lengua oficial, la española, pierde peso frente a la obsesión autonómica de proteger su lengua propia.

\subsection{El marco jurídico autonómico del bilingüismo}

El desarrollo del Estado de las Autonomías ha llevado a un complejo panorama legislativo, en cuanto a la protección del patrimonio lingüístico y cultural se refiere. De hecho, de las 17 Comunidades Autónomas españolas, sólo tres de ellas (Murcia, Castilla La Mancha y la Comunidad de Madrid), junto con la Ciudad Autónoma de Ceuta, no cuentan con una legislación específica de protección de su patrimonio lingüístico y/o cultural.

\footnotetext{
29 BLANCO VALDÉS, Roberto L. op.cit., 2013, p. 490.
}

30 RUBIO LLORENTE, Francisco, op.cit., 2001, p. 52. 
Por ejemplo, el artículo 6 del Estatuto de Autonomía del País Vasco ${ }^{31}$ protege y regula el uso del euskera, como patrimonio del País Vasco y de otros territorios y comunidades, así como desarrolla el precepto mediante la Ley Vasca 10/1982, de 24 de noviembre, básica de normalización del uso del euskera. En el caso navarro, hay que destacar la existencia de la Ley Orgánica 13/1982, de 10 de agosto, de reintegración y amejoramiento del régimen foral de Navarra, que recoge en el artículo 9 el reconocimiento del castellano como la lengua oficial de Navarra y del vascuence como lengua oficial en las zonas vascoparlantes, cuya regulación se recoge en la Ley Foral 18/1996, de 15 de diciembre, del vascuence. Por su parte, el artículo 3 del Estatuto de Autonomía catalán y el artículo 6 del Estatuto posterior de $2006^{32}$ regulan el catalán como lengua oficial del territorio, junto con el castellano. Los derechos lingüísticos catalanes se desarrollan en la Ley catalana 17/1998, de 7 de enero, de política lingüística, al tiempo que se protege el aranés en la Ley catalana 16/1990, de 13 de julio del Régimen especial del valle de Arán. En las Islas Baleares, el artículo 3 del Estatuto de Autonomía de 1983 reconocía la lengua catalana junto con la castellana como idiomas oficiales, por lo que la Ley Balear 3/1986, de 19 de abril, de normalización lingüística sirvió para desarrollar el artículo 3 del Estatuto con la finalidad de garantizar el uso del catalán y del castellano en dicha Comunidad Autónoma. Años después, el Estatuto de Autonomía de 2007 dispuso en su artículo 4 que la lengua propia es el catalán, la cual a su vez tendrá carácter oficial junto a la lengua (ajena) castellana, como ocurría en Cataluña. En la Comunidad Valenciana, el Estatuto ${ }^{33}$ de 1982 protegía la lengua en el artículo 7, precepto que se desarrolla posteriormente mediante la Ley valenciana 4/1983, de 23 de noviembre, de uso y enseñanza del valenciano. En la modificación estatutaria de 2006 será el artículo 6 el que recoja lo relativo a la lengua, disponiendo que la lengua propia de la Comunitat Valenciana es el valenciano, la cual es a su vez lengua oficial junto con el castellano, «el idioma oficial del Estado». Ello implica que «todos tienen derecho a conocerlos y a usarlos y a recibir la enseñanza del, y en, idioma valenciano», por lo que el apartado 3 dispone la obligación del gobierno valenciano de garantizar «el uso normal y oficial de las dos lenguas, y adoptará las medidas necesarias para asegurar su conocimiento». En consecuencia, nadie podrá ser discriminado por razón de su lengua, aunque se otorgará especial protección y respeto a la recuperación del valenciano. En cualquier caso,

31 Estatuto de Autonomía P. Vasco https://www.boe.es/buscar/act.php?id=BOE-A-1979-30177

32 Artículo 6.2 Estatuto de Cataluña: «El catalán es la lengua oficial de Cataluña. También lo es el castellano, que es la lengua oficial del Estado español. Todas las personas tienen derecho a utilizar las dos lenguas oficiales y los ciudadanos de Cataluña el derecho y el deber de conocerlas. Los poderes públicos de Cataluña deben establecer las medidas necesarias para facilitar el ejercicio de estos derechos y el cumplimiento de este deber. De acuerdo con lo dispuesto en el artículo 32, no puede haber discriminación por el uso de una u otra lengua».

33 Ley Orgánica 5/1982, de 1 de julio, de Estatuto de Autonomía de la Comunidad Valenciana. https://www.boe.es/buscar/act.php?id=BOE-A-1982-17235\&p=20100717\&tn=6 Ley Orgánica 1/2006, de 10 de abril, de Reforma de Ley Orgánica 5/1982, de 1 de julio, de Estatuto de Autonomía de la Comunidad Valenciana http://www.congreso.es/consti/estatutos/ind_estatutos.jsp?com=79 
como no todos los territorios son valenciano-parlantes, el apartado séptimo dispone que «se delimitarán por ley los territorios en los que predomine el uso de una y otra lengua, así como los que puedan ser exceptuados de la enseñanza y del uso de la lengua propia de la Comunitat Valenciana». En este caso, no se habla de catalán (pese a que la Generalitat de Catalunya considere que en la Comunidad Valenciana también se habla su lengua propia), por lo que hay una referencia expresa a la Acadèmia Valenciana de la Llengua, como la institución normativa del idioma valenciano. En Galicia, por su parte el artículo 5 del Estatuto de Autonomía garantiza y protege el uso del gallego, para lo cual se aprobó la Ley gallega 3/1983, de 15 de junio, de normalización lingüística. En el caso de Asturias, el Estatuto de Autonomía ${ }^{34}$ protege el bable en su artículo 4, así como se ha aprobado la Ley asturiana 1/1998, de 23 de marzo, de uso y protección del bable/asturiano. En Aragón, el Estatuto protege las lenguas y modalidades lingüísticas de Aragón, en el artículo 7, que se ha desarrollado en la Ley aragonesa 3/1999, de 10 de marzo del patrimonio cultural aragonés, así como en Ley 10/2009, de 22 de diciembre, de uso, protección y promoción de las lenguas propias de Aragón. Mientras, en Extremadura, el artículo 11 del Estatuto de Autonomía se protegen las peculiaridades lingüísticas y culturales, al tiempo que el artículo 60 de la Ley extremeña 4/1999, de 29 de marzo, de patrimonio histórico y cultural de Extremadura protege como bienes intangibles la tradición oral, el habla y las peculiaridades lingüísticas de Extremadura. Así como el Decreto 45/2001, de 20 de marzo, declara bien de interés cultural la «A Fala» (habla viva del valle de Xálama). En Andalucía, el Estatuto de 1981 y el de $2007^{35}$ se refieren en su artículo 10.3 al "afianzamiento de la conciencia de identidad y de la cultura andaluza a través del conocimiento, investigación y difusión del patrimonio bistórico, antropológico y lingüístico». Asimismo, en el marco de la defensa del patrimonio artístico, cultural y natural, Castilla y León protege la lengua castellana como parte de su patrimonio en el artículo 4 del Estatuto de Autonomía, así como cuenta con la Ley castellano leonesa 12/2002, de 11 de julio, de patrimonio cultural de Castilla y León. Por último, desde una perspectiva amplia en materia cultural, en Cantabria se aprobó la Ley 11/1998, de 13 de octubre, del patrimonio cultural de Cantabria, así como La Rioja aprobó la Ley riojana 7/2004, de 18 de octubre, de patrimonio cultural, histórico y artístico de La Rioja. Mientras, en Canarias cabe destacar la Ley canaria 4/1999, de 15 de marzo, de patrimonio histórico de Canarias, donde el artículo 73 reconoce las formas de expresión y transmisión de la cultura tradicional del pueblo canario. Para finalizar este repaso por la legislación autonómica, cabe citar el caso de la Ciudad Autónoma de Melilla, cuyo Estatuto de Autonomía señala, en el artículo 5, como objetivo básico de Melilla la «promoción y estímulo de los calores de comprensión, respeto y aprecio de la pluralidad cultural y lingüística de la población melillense».

34 Ley Orgánica 7/1981, de 30 de diciembre, de Estatuto de Autonomía para Asturias. https://www.boe.es/buscar/act.php?id=BOE-A-1982-634

35 Ley Orgánica 2/2007, de 19 de marzo, de reforma del Estatuto de Autonomía para Andalucía., disponible en https://www.boe.es/buscar/act.php?id=BOE-A-2007-5825 
Para Eliseo $\mathrm{Aja}^{36}$, todas las leyes autonómicas que han reconocido una lengua cooficial pivotan en torno a dos ejes: la cooficialidad y la normalización social. Por cooficialidad se entenderá el derecho de los ciudadanos a utilizar cualquiera de las dos lenguas, siendo el ciudadano quien tiene la preferencia de escoger la lengua de relación con la Administración, con plenos efectos jurídicos. La normalización lingüística, por su parte, se refiere a la promoción del conocimiento y del uso de las lenguas cooficiales en todos los ámbitos de la sociedad (tanto públicos como privados), para lo cual serán claves los medios de comunicación autonómicos. Ello se ha traducido no en un modelo de promoción e igualación de las lenguas, sino en el desarrollo de un modelo lingüístico centrado en la lengua cooficial, en detrimento del castellano.

Otra característica común a la normativa autonómica es que definen una lengua como «propia» (además de cooficial), mientras que la otra simplemente es oficial. Ello sentaría las bases de una diferencia que va más allá de lo nominal, ya que supondría un trato jurídico diferente. El frío término oficial se contrapone a la calidez de la lengua propia. Por ello, para Blanco Valdés, «cuando los Estatutos proclaman que la lengua española es oficial y la lengua vernácula es la propia (aunque sea también oficial) a lo que se está apuntando es que la primera es una lengua ajena (o extraña) al territorio, en la que el castellano es oficial por el mero hecho administrativo de que lo es en toda España, mientras que la lengua vernácula es la propia, la de ese territorio: la que manejan los hablantes auténticos» ${ }^{37}$.

La lengua propia o vernácula ha pasado así a un estadio superior en el imaginario ciudadano, en el sistema educativo, en los medios de comunicación y, obviamente también, en las instituciones autonómicas. Reivindicar los derechos de la lengua autóctona es jurídicamente posible e incluso forma parte del mandato constitucional. El derecho de la lengua a crearse hablantes obligatorios no. Tan grave es el desarrollo de la política lingüística autonómica que Roberto L. Blanco Valdés califica España como «el mayor laboratorio europeo de la normalización lingüistica» ${ }^{38}$. Un laboratorio en que se han empleado herramientas de ingeniería social para generar una «renacionalización lingüística» ${ }^{39}$, paralela a «la desnacionalización de España y de la lengua común de los españoles» ${ }^{40}$.

\subsection{La jurisprudencia sobre la lengua castellana}

El Tribunal Constitucional es consciente de la complejidad de la cuestión lingüística, como quedó reflejado en su sentencia STC 205/1990, de 13 de diciembre, en la que afirmaba que «la ordenación del pluralismo lingüístico presenta una notable com-

36 AJA, Eliseo, op.cit., 2007, p. 179

37 BLANCO VALDÉS, Roberto L. op.cit., 2013, p. 483.

38 BLANCO VALDÉS, Roberto L. op.cit., 2013, p. 479.

39 Ibidem

${ }^{40}$ Ibidem 
plejidad, no sólo por las dificultades para precisar el alcance de los mandatos constitucionales y legales que versan sobre esta cuestión (...), sino también por incidir sobre materias de considerable importancia simbólica y afectiva en la estructuración autonómica del Estado».

En esta línea, el Tribunal Constitucional ${ }^{41}$ ha afirmado que sólo del castellano se establece constitucionalmente un deber individualizado de conocimiento, y con él la presunción de que todos los españoles lo conocen (SSTC 82/86 ${ }^{42}$ y 84/86 ${ }^{43}$ ). Más aún, el Alto Tribunal ha señalado que «no existe un deber constitucional de conocimiento de una lengua cooficial» (STC 84/1986 ${ }^{44}$ ). Si bien, «la instauración por el art. 3.2 de la Constitución de la cooficialidad de las respectivas lenguas españolas en determinadas Comunidades Autónomas tiene consecuencias para todos los poderes públicos en dichas Comunidades, y en primer término el derecho de los ciudadanos a usar cualquiera de las dos lenguas ante cualquier administración en la Comunidad respectiva con plena eficacia jurídica» (STC 82/1986 ${ }^{45}$ ). En otras palabras, como señala el Tribunal Constitucional, en los territorios dotados de un estatuto de cooficialidad lingüística el uso de los particulares de cualquier lengua oficial tiene efectivamente plena validez jurídica, siendo el derecho de las personas al uso de una lengua oficial un derecho fundado en la Constitución y el respectivo Estatuto de Autonomía (STC 82/1986 ${ }^{46}$ y $123 / 1988^{47}$ ).

Por consiguiente, el bilingüismo debe ser expresión de convivencia, no de enfrentamiento, fruto del calificativo «común» con que se refiere la Constitución a dicho patrimonio. En suma, como ha señalado el Tribunal Constitucional, en su sentencia STC 337/1994, de 23 de diciembre, «el régimen de cooficialidad lingüística establecido por la Constitución y los Estatutos de Autonomía presupone no sólo la coexistencia sino la convivencia de ambas lenguas oficiales, para preservar el bilingüismo existente en aquellas Comunidades Autónomas que cuentan con una lengua propia y que constituye por sí misma una parte del patrimonio cultural al que se refiere el artículo 3.3 CE».

En palabras del Tribunal Constitucional, «la exigencia del bilingüismo ba de llevarse a cabo con un criterio de racionalidad y proporcionalidad, desde la perspectiva de lo dispuesto en los artículos 23.1, 139.1 y 149.1.1..$^{\circ}$ de la Constitución» (STC 82/8648). De modo que «el régimen de cooficialidad lingüistica (...) presupone no sólo la coexistencia sino la convivencia de ambas lenguas cooficiales (...). Los poderes públicos deben garantizar, en sus

${ }^{4}$ Véase la compilación de la jurisprudencia de la sinopsis del artículo 3 del Portal de la Constitución del Congreso, en http://www.congreso.es/consti/constitucion/indice/sinopsis/sinopsis. jsp?art=3\&tipo=2 Fecha de consulta: 7 febrero 2017 .

${ }^{42}$ http://www.congreso.es/constitucion/ficheros/sentencias/stc_082_1986.pdf Fecha: 15 enero 2017.

43 http://www.congreso.es/constitucion/ficheros/sentencias/stc_084_1986.pdf Fecha: 15 enero 2017.

44 http://www.congreso.es/constitucion/ficheros/sentencias/stc_084_1986.pdf Fecha: 24 enero 2017.

45 http://www.congreso.es/constitucion/ficheros/sentencias/stc_082_1986.pdf Fecha: 20 enero 2017.

46 http://www.congreso.es/constitucion/ficheros/sentencias/stc_082_1986.pdf Fecha: 2 marzo 2017.

47 http://www.congreso.es/constitucion/ficheros/sentencias/stc_123_1988.pdf Fecha: 2 marzo 2017.

48 Véase STC 82/86 en http://www.congreso.es/constitucion/ficheros/sentencias/stc_082_1986.pdf Fecha de consulta: 2 marzo 2017. 
respectivos ámbitos de competencia el derecho de todos a no ser discriminados por el uso de una de lenguas oficiales en la Comunidad Autónoma» (STC 337/1994 ${ }^{49}$ ).

De forma más reciente, en su sentencia 31/2010, de 28 de junio, relativa a la Ley Orgánica 6/2006, de 19 de julio, de Reforma del Estatuto de Autonomía de Cataluña, el Alto Tribunal declaraba inconstitucional la referencia «y preferente» del artículo 6.1 del Estatuto. Ese artículo decía originariamente que «la lengua propia de Cataluña es el catalán. Como tal, el catalán es la lengua de uso normal y preferente de las administraciones públicas y de los medios de comunicación públicos de Cataluña, y es también la lengua normalmente utilizada como vebicular y de aprendizaje en la enseñanza». Cierto es que es la lengua más empleada, pero no por ello, efectivamente, es la lengua precedente. Este hecho resulta paradójico, ya que el TCE, parece desconocer la práctica de la política lingüista catalana, que ha impregnado la sociedad paulatinamente, cuando señala que la ausencia de toda referencia al castellano como lengua docente en el artículo 35.1 no supone «un propósito deliberado de exclusión del castellano», puesto que «el precepto estatutario se limita a señalar el deber de utilizar el catalán normalmente como lengua vehicula y de aprendizaje» (F.J.24), pero no como la única, sin impedir por ello la utilización del castellano.

El Tribunal fue criticado a su vez por su falta de contundencia, por autores como Roberto L. Blanco Valdés ${ }^{50}$, Muñoz Machado ${ }^{51}$ o Ángel Luís Alonso de Antonio ${ }^{52}$, ya que anula un inciso de un único artículo, pero abusando del criterio interpretativo, condicionando la constitucionalidad de varios preceptos a lo que el Tribunal Constitucional señala en los respectivos fundamentos jurídicos. Por ello, Alonso de Antonio subraya «que las decisiones del Tribunal Constitucional en el terreno de la lengua han sido escasamente respetuosas con el castellano como única lengua oficial del Estado, que no se han querido resolver en el fondo las cuestiones prácticas, como la enseñanza, que se suscitan a diario y por la vía, ingenua a veces, de la interpretación de los artículos recurridos se abre la puerta a unas decisiones políticas que pueden poner en peligro la igualdad de derechos de los ciudadanos de Cataluña según la lengua que tengan de uso común» ${ }^{53}$. En la misma línea, Blanco Valdés afirma que «con un criterio abiertamente discutible, el Tribunal prefirió (...) crear derecho en lugar de anular el que era manifiestamente contrario a la Constitución, con lo que, paradójicamente, su pretendida voluntad de intervención mínima, se convertirá en una intervención, sino máxima, sí muy superior» ${ }^{54}$.

49 Véase STC 337/1994 en http://www.congreso.es/constitucion/ficheros/sentencias/stc_337_1994. pdf Fecha de consulta: 2 marzo 2017.

50 BLANCO VALDÉS, Roberto L. op.cit., 2013, pp. 497-499.

51 MUÑOZ MACHADO, S., «Dentro de los términos de la presente Constitución», en El Cronista del Estado Social y Democrático de Derecho, núm. 15, 2010, pág. 6.

52 ALONSO DE ANTONIO, Ángel Luís, «La cuestión lingüística en la sentencia del Tribunal Constitucional sobre el Estatuto de Autonomía de Cataluña», UNED. Teoría y Realidad Constitucional, núm. 27, 2011, pp. 449-460

53 Ibidem, p. 458.

54 BLANCO VALDÉS, Roberto L. op.cit., 2013, p. 499 
Paradójicamente, esta sentencia fue rechazada también por el independentismo catalán, como muestran las palabras del catedrático y Conseller de la Generalitat, Jaume Vernet, ya que según él «desbarató el régimen jurídico-lingüístico establecido por el Estatut, que ya llevaba aplicándose con normalidad desde años atrás, y que se basaba en la concepción normativa de lengua propia y en la doble oficialidad» ${ }^{55}$. Esa normalidad a la que alude Jaume Vernet es, en realidad, el anormal cumplimiento del ordenamiento jurídico español, fruto de la dejadez de las instituciones nacionales y de una jurisprudencia laxa y, en ocasiones, contradictoria.

Otra polémica reciente sentencia, en este caso del Tribunal Supremo (STS STS $1668 / 2015$ de 23 de abril de 2015) dispone que se considera razonable fijar en un 25 $\%$ el uso del castellano en las escuelas de Cataluña, incluyendo una asignatura troncal. La Sala Tercera avala así el porcentaje fijado por el TSJ de Cataluña al ejecutar las sentencias dictadas por el alto tribunal desde 2010, aunque dispone (F.J.3) que «no pueda aceptarse la exclusividad del catalán como lengua única vehicular en la enseñanza, por lo que el castellano ba de utilizarse también como lengua de esa naturaleza en el sistema educativo de Cataluña "en la proporción que proceda dado el estado de normalización lingüística alcanzado por la sociedad catalana, de modo que el mismo no quede reducido en su uso al de objeto de estudio de una asignatura más, sino que se haga efectiva su utilización como lengua docente y vebicular en la enseñanza» ${ }^{56}$. Este avance resulta, a todas luces insuficiente. Parece que la normalización lingüística catalana o, mejor dicho, la renacionalización lingüística implica la aceptación de la desnacionalización española en suelo catalán.

\subsection{El derecho a conocer las leyes y acceder a la información pública en lengua castellana}

Los españoles estamos sujetos a la Constitución y al resto del ordenamiento jurídico, como dispone el artículo $9 \mathrm{CE}$, por lo que la publicidad de las normas que nos vinculan es uno de los ejes clave de todo Estado de Derecho. El primer apartado del artículo 9 declara de forma expresa que, tanto los ciudadanos, como los poderes públicos están sujetos a la Constitución y al resto del ordenamiento jurídico. Por ello, el segundo apartado dispone que corresponde a los poderes públicos promover las condiciones para que la libertad y la igualdad del individuo y de los grupos en que se integra sean reales y efectivas, lo que supone remover los obstáculos que impidan o dificulten su plenitud y facilitar la participación de todos los ciudadanos en la vida política, económica, cultural y social. Uno de los aspectos a tener en cuenta también en dicha participación en la vida pública está vinculado a la lengua en la que los ciudadanos participan en dicha vida política, económica, cultural o social. Para el

55 VERNET I LLOBET, Jaume, «La perspectiva catalana en torno a la reforma constitucional de la estructura territorial del estado», Revista Española de la Función Consultiva, núm. 20, julio-diciembre (2013), págs. 79-109, p. 88, http://portales.gva.es/cjccv/pdfs/pub/refc-n20.pdf

56 STS 1668/2015 de 23 de abril de 2015, disponible en https:/www.iberley.es/jurisprudencia/ sentencia-administrativo-ts-sala-contencioso-sec-4-rec-2548-2014-23-04-2015-46903261 
Tribunal Constitucional (STC 39/1986, de 31 de marzo), el artículo 9.2 CE «es un precepto que compromete la acción de los poderes públicos, a fin de que pueda alcanzarse la igualdad sustancial entre los individuos, con independencia de su situación social» ${ }^{57}$. Así pues, el principio de igualdad del 9.2 implicaría que la no traducción de la ley afecta a la discriminación de los castellano-parlantes porque les coloca en una situación de inferioridad, al no poder conocer la ley.

La no traducción de las normas al español no solo supondría una discriminación para los castellano parlantes, sino también un supuesto de inseguridad jurídica. El Tribunal Constitucional ha dedicado numerosas sentencias al concepto de seguridad jurídica. La seguridad jurídica sería para el Tribunal «suma de certeza y legalidad, jerarquía y publicidad normativa, irretroactividad de lo no favorable, interdicción de la arbitrariedad, pero que, si se agotara en la adición de estos principios, no bubiera precisado de ser formulada expresamente. La seguridad jurídica es la suma de estos principios, equilibrada de tal suerte que permita promover, en el orden jurídico, la justicia y la igualdad, en libertad ${ }^{58}$, según la Sentencia del Tribunal Constitucional 27/1981, de 20 de julio. Por ello, el legislador debe perseguir la claridad y no la confusión normativa. De la jurisprudencia del Constitucional se deduce que la seguridad jurídica despliega sus efectos en diferentes ámbitos, que abarcan a todo el proceso de creación y aplicación del Derecho.

Asimismo, el apartado tercero del artículo 9 exige la publicidad de las normas. De forma expresa, la Constitución garantiza el principio de legalidad, la jerarquía normativa, la publicidad de las normas, la irretroactividad de las disposiciones sancionadoras no favorables o restrictivas de derechos individuales, la seguridad jurídica, la responsabilidad y la interdicción de la arbitrariedad de los poderes públicos. Por ello, el artículo 9.3 también afectaría al principio fundamental de seguridad jurídica, en la medida en que no poder conocer el contenido de la ley produce inseguridad jurídica. La seguridad jurídica implica principalmente dos exigencias para el ordenamiento jurídico: por un lado, la publicidad de las normas, vinculada a la posibilidad de exigir su cumplimiento, y, por otro, la irretroactividad de las mismas.

El Tribunal Constitucional en su sentencia 179/1989, de 2 de noviembre, señaló que: «La Constitución, en su artículo 9.3, garantiza el principio de la publicidad de las normas. Esta garantía aparece como consecuencia ineluctable de la proclamación de España como un Estado de derecho, y se encuentra en intima relación con el principio de seguridad jurídica consagrado en el mismo art. 9.3 C.E., pues sólo podrán asegurarse las posiciones jurídicas de los ciudadanos, la posibilidad de éstos de ejercer y defender sus derechos, y la efectiva sujeción de los ciudadanos y los poderes públicos al ordenamiento jurídico, si los destinatarios de las normas tienen una efectiva oportunidad de conocerlas en cuanto tales normas, mediante un

57 STC 39/1986, de 31 de marzo, disponible en http:/www.congreso.es/constitucion/ficheros/ sentencias/stc_039_1986.pdf

58 STC 27/1981, de 20 de julio, disponible en https:/guiasjuridicas.wolterskluwer.es/Content/ Documento.aspx? params= H4sIAAAAAAAEAMtMSbF1jTAAAUMTQxNztbLUouLM_ DxbIwMDCwNzAwuQQGZapUt-ckhlQaptWmJOcSoAwrlbTjUAAAA=WKE\#I7 
instrumento de difusión general que dé fe de su existencia y contenido, por lo que resultarán evidentemente contrarias al principio de publicidad aquellas normas que fueran de imposible o muy difícil conocimiento» 59 .

Por ende, de la redacción del artículo 9 se puede deducir además, que no se puede obedecer algo que no se publicita en la lengua común a todos los españoles o en una lengua que no se entiende (recuérdese que todos los españoles dominan el español, pero no siempre son bilingües). Por ello, la exigencia constitucional de la publicidad de las normas (artículo 9.3) supone también que se publiquen en lengua castellana, en virtud del artículo $3 \mathrm{CE}$. Sobra decir que la carga de conocer la ley es del ciudadano, ya que, como dice el artículo 6 del Código Civil la ignorancia de la ley no exime de su cumplimiento. Entonces, si son los poderes públicos quienes impiden a los ciudadanos conocer el derecho, sería más reprobable aún la imposibilidad de conocer la norma en su propia lengua. Díez Picazo y Gullón Ballesteros nos recuerdan, al respecto que «si la norma jurídica contiene un deber de observancia de una determinada conducta o comportamiento, es claro que el comportamiento o la conducta debidos no pueden ser dejados al arbitrio del destinatario de las normas. La ignorancia o el desconocimiento de la existencia o del contenido o alcance de las reglas de Derecho no puede servir de excusa de la falta de cumplimiento» ${ }^{60}$. Por ello, los poderes públicos (lo que incluye a los autonómicos) no pueden hacer caso omiso del artículo 3CE, en lo relativo al artículo 9CE y la propia Ley de Transparencia.

La exigencia de la publicidad no sólo se recoge en nuestra Constitución, en el ámbito europeo, es importante citar el Convenio 205 del Consejo de Europa, de Acceso a los Documentos Públicos (CEADP), de 18 de junio de 2009. Este acuerdo es un instrumento de colaboración internacional en materia de transparencia, si bien no ha sido aún suscrito por España y tampoco ha entrado en vigor al no haberse alcanzado el número países (diez) requeridos por el artículo 16 del propio Convenio. En la Unión Europea, el artículo 15.3 (antiguo 255 TCE) del Tratado de Funcionamiento de la Unión, lo configura como un derecho de todo ciudadano de la Unión, así como de toda persona física o jurídica que resida o tenga su domicilio social en un Estado miembro. De la misma forma se pronuncia el artículo 42 de la Carta de los Derechos Fundamentales de la Unión Europea. El desarrollo normativo de esta previsión de los Tratados se encuentra en el Reglamento CE/1049/2001, del Parlamento Europeo y del Consejo de 30 de mayo de 2001, relativo al acceso del público a los documentos del Parlamento Europeo, del Consejo y de la Comisión.

A todo ello se suma la exigencia de permitir el acceso a la información pública, tal y como dispone la Ley 19/2013 de Transparencia, Acceso a la Información Pública y Buen Gobierno. Dicha Ley ha sido desarrollada por el Real Decreto 919/2014, de 31 de octubre, por el que se aprueba el Estatuto del Consejo de Transparencia y

59 Véase sinopsis del artículo del Congreso de los Diputados, disponible en http://www.congreso. es/consti/constitucion/indice/sinopsis/sinopsis.jsp?art $=9 \&$ tipo $=2$

${ }^{60}$ DÍEZ-PICAZO, L., y GULLÓN BALLESTEROS, A., Sistema de Derecho Civil, volumen I, $4{ }^{\mathrm{a}}$ edición, Ed. Tecnos, Madrid, 1981, págs. 222 y 223. 
Buen Gobierno. La Ley de Transparencia es una ley muy esperada, desde que el artículo $10.5 \mathrm{~b}$ de la Constitución dispusiera la necesidad de regular mediante una ley «el acceso de los ciudadanos a los archivos y registros administrativos, salvo en lo que afecte a la seguridad y defensa del Estado, la averiguación de los delitos y la intimidad de las personas». Esta previsión constitucional de reserva de ley se articuló a través del artículo 37 de la Ley 30/1992, de 26 de noviembre, de Régimen Jurídico de las Administraciones Públicas y del Procedimiento Administrativo Común (LRJAPPAC), el cual estableció como derecho de los ciudadanos el poder acceder a los registros y a los documentos que, formando parte de un expediente, obraran en los archivos administrativos (con independencia del soporte), siempre que tales expedientes correspondieran a procedimientos terminados en la fecha de la solicitud. Este derecho incluía la obtención de copias o certificados de los documentos cuyo examen fuera autorizado por la Administración. La Ley 30/1992 resultaba insuficiente, sin embargo, y hacía falta una norma ad hoc de transparencia. Así pues, como nos recuerda Aranzazu Moretón Toquero, «en un Estado democrático de Derecho la publicidad sirve, con carácter general, para alcanzar la transparencia que permite que los ciudadanos pueden visibilizar el funcionamiento de las Administraciones y, en general, el ejercicio del poder público, lo que cumple, en primer término, una misión evidente: la de permitir el control de dicha actividad y su sometimiento a la legalidad limitando la arbitrariedad, exigencia consustancial al Estado de Derecho» ${ }^{61}$.

España ha tardado mucho en afrontar esta cuestión a diferencia de otros países europeos y americanos ${ }^{62}$. El objeto de la Ley (artículo 1) es ampliar y reforzar la transparencia pública, regulando el derecho de acceso a la información pública y estableciendo las obligaciones de buen gobierno que deben cumplir los responsables públicos, así como las consecuencias derivadas de su incumplimiento. Como legislación básica del Estado, esta norma es aplicable a todas las Administraciones públicas, con base en las competencias exclusivas del Estado contempladas en el artículo 149.1 CE, apartados $1 .^{\circ}$ (garantía de la igualdad de todos los españoles en derechos y deberes),

${ }^{61}$ Vid. MORETÓN TOQUERO, M. ${ }^{a}$ Aranzazu, op.cit., p. 4, disponible en https://dialnet.unirioja. es/ejemplar/365711 Fecha de consulta: 5 febrero 2017

62 En la década de los sesenta y setenta son pioneros al respecto: Estados Unidos con su Freedom of Information Act (1966), y Dinamarca y Noruega con una ley similar en 1970. Le siguen: Francia 1978, Grecia 1986, Austria 1987, Italia 1990, Holanda 1991, Portugal 1993, Australia y Nueva Zelanda en 1982 y Canadá en 1983. Tras la caída de la URSS, regulan leyes de transparencia: República Checa 1999, Bulgaria 2000, Polonia 2001, Serbia 2003 o Rusia 2009. Son recientes las leyes de Reino Unido en 2000 o Alemania en 2005. En América Latina, hay países destacados como México 2002, Perú 2003, Argentina 2004, Chile 2008, Uruguay 2008 o Brasil 2011. Fuente: GUICHOT REINA, Emilio (Coord.), Transparencia, acceso a la información pública y buen gobierno. Estudio de la Ley 19/2013, de 9 de diciembre, Editorial Tecnos-Instituto Universitario García Oviedo, Madrid, 2014. FERNANDEZ LUQUE, José Manuel, «El marco jurídico de la Transparencia en España», Revista de la Escuela Jacobea de Posgrado, N. ${ }^{\circ}$ 12, junio 2017, págs. $123-152$ (p.131), disponible en http://www.jacobea.edu.mx/ revista/numeros/numero12/6.Marco_legal_transparencia.\%20Jose_Manuel_Fernandez_Luque.pdf Fecha de consulta: 24 noviembre 2017 
$13 .^{\circ}$ (planificación general de la actividad económica) y $18 .^{\circ}$ (bases del régimen jurídico de las Administraciones públicas), tal como dispone su disposición final octava.

La Ley 19/2013 no parte de cero, la propia Constitución obliga a la publicidad de las normas, así como había disposiciones relativas a la información pública. En esta línea, la Ley amplía y refuerza las obligaciones de publicidad activa ${ }^{63}$. Concretamente, en materia de información institucional, organizativa y de planificación exige la publicación de información relativa a las funciones que desarrollan, la normativa que les resulta de aplicación y su estructura organizativa, además de sus instrumentos de planificación y la evaluación de su grado de cumplimiento. En materia de información de relevancia jurídica, la Ley contiene un amplio repertorio de documentos que, al ser publicados, proporcionarán una mayor seguridad jurídica. En el ámbito de la información de relevancia económica, presupuestaria y estadística, se establece un catálogo que debe ser accesible, para el control de la gestión y utilización de los recursos públicos. Igualmente, se establece la obligación de publicar toda la información que sea generalmente objeto de solicitud de acceso por parte de los ciudadanos.

La Ley establece el principio de publicidad activa de la información cuyo conocimiento sea relevante garantizar al ciudadano, lo que incluye la remisión a un catálogo sobre el tipo de información que se entiende por «relevante». Aquí hay un amplio campo que debe ser regulado a nivel autonómico y local y cuya publicación debe hacerse en las correspondientes sedes electrónicas o páginas web, en relación a las cuales Emilio Guichot afirma que «la práctica de los portales (de transparencia) desvela, basta el momento, prácticas discutibles o directamente contrarias a esta regulación, como la falta de publicación de determinados contratos menores, la publicación de las resoluciones de compatibilidad de empleados públicos, sin identificación de las personas beneficiarias, etc. ${ }^{64}$ »

En paralelo a la publicidad activa, hay que hablar de la publicidad pasiva o derecho de acceso a la información pública. El plazo establecido por la Ley es de un máximo de un mes desde la recepción por el órgano competente a resolver, ampliable a otro mes en caso que el volumen o la complejidad de la información solicitada sean elevados, previa notificación al solicitante. Ahora bien, como recuerda Gichot «resulta evidente que la efectividad del derecho de los ciudadanos dependerá en buena medida de que los sujetos respondan de becho en plazo y que no se escuden en respuestas que nieguen la propia existencia de información» ${ }^{65}$. Ahora bien, frente a la desestimación expresa o presunta

63 La Ley regula el ámbito subjetivo de aplicación de la norma (artículos 2 a 4, y disposiciones adicionales sexta y octava), la publicidad activa y la información objeto de ésta (artículos 5 a 11 y disposición adicional tercera), el derecho de acceso a la información pública, los límites a la transparencia y el procedimiento a seguir para solicitar el acceso a demanda (artículos 12 a 22 y disposición adicional quinta), el régimen de recursos (artículos 23 y 24 y disposición adicional cuarta), el buen gobierno y su régimen sancionador (artículos 25 a 32), el Consejo de Transparencia y Buen Gobierno (artículos 33 a 40) y la aplicación únicamente supletoria de la Ley 19/2013 a las regulaciones especiales del derecho de acceso a la información pública (disposición adicional primera).

${ }^{64}$ GUICHOT, Emilio, «Reflexiones sobre la aplicación de la nueva normativa sobre transparencia», Revista Andaluza de Administración Pública, núm. 94, Sevilla, enero-abril (2016), pp. 89-106 (p.100).

65 Ibidem, pp. 100-101. 
cabe interponer una reclamación ante la autoridad independiente de control en el plazo de un mes, así como cabe un recurso ante la jurisdicción contencioso-administrativa. Otro problema serían las causas de inadmisión, ya que con ellas se juega en ocasiones con la efectividad del derecho de acceso, al responder que la información está «en curso de elaboración o de publicación general», por ejemplo ${ }^{66}$.

Para velar por la transparencia, la Ley regula la creación de una autoridad administrativa nueva: el Consejo de Transparencia y Buen Gobierno, cuyo Presidente es nombrado por el Gobierno y ratificado por el Congreso de los Diputados por mayoría absoluta. La disposición adicional cuarta de la Ley permite que las Comunidades Autónomas puedan atribuir la resolución de las reclamaciones ciudadanas a tal Consejo, previo convenio con la Administración General del Estado. Se han acogido a esta modalidad: Asturias, Cantabria, Castilla la Mancha, la Rioja, Extremadura y Ceuta. Si bien, lo habitual ha sido la creación de instituciones autonómicas nuevas de transparencia, excepto en el caso de Castilla y León y Galicia, que han residenciado la competencia de la resolución de las reclamaciones en el Defensor del Pueblo autonómico.

La Ley de Transparencia busca cumplir así con su doble cometido de control (del poder público) y protección (de los ciudadanos). Para Jesús Lizcano Álvarez, Presidente de Transparencia Internacional en España, la transparencia posibilita «un cierto control de los poderes públicos por parte de la sociedad civil, y por tanto, una berramienta fundamental de lucha contra la corrupción, verdadera lacra social que perjudica enormemente la justicia social y el desarrollo económico e institucional en buena parte de los países del mun$d 0{ }^{67}$. Sin embargo, para gran parte de la doctrina, se ha perdido la oportunidad de configurar legalmente el derecho de acceso como un derecho fundamental en España.

Son muchos los autores que sostienen que la Ley 19/2013 ha decepcionado las expectativas, entre los que se encuentran Aranzazu Moretón Toquero ${ }^{68}$, Fernando Rey Martínez $^{69}$ o Manuel Sánchez de Diego, porque la Ley ha abordado la exigencia de una transparencia y buen gobierno desde la perspectiva del derecho administrativo y no desde la perspectiva del derecho constitucional. De hecho, Manuel Sánchez de Diego considera negativo que «el anclaje constitucional de la Ley se encuentra sólo en el artículo 105 B) de la Constitución», a lo que se añade que «en su propia exposición de motivos se dice en la Ley se avanza y se profundiza en la configuración de obligaciones de publi-

66 Ibidem, p. 101.

${ }^{67}$ LIZCANO ÁLVAREZ, J., «Transparencia y corrupción. Un análisis desde la sociedad civil», en PAU i VALL (Coord.), La transparencia desde el Parlamento. XXI Jornadas de la Asociación Española de Letrados de Parlamentos, Aelpa-Tecnos, Madrid, 2015, pág. 80.

68 MORETÓN TOQUERO, M. ${ }^{a}$ Aranzazu, «Los límites del derecho de acceso a la información pública», en Revista Jurídica de Castilla y León, n. 33 , mayo 2014, 24 pp., disponible en https://dialnet. unirioja.es/ejemplar/365711 Fecha de consulta: 5 febrero 2017

69 REY MARTÍNEZ, Fernando, «Quod omnes tangit ab omnibus cognitum esse debet: El derecho de acceso a la información pública como derecho fundamental», en Revista Jurídica de Castilla y León, n. ${ }^{\circ} 33$, mayo 2014, 19 pp., disponible en https://dialnet.unirioja.es/ejemplar/365711 Fecha: 5 febrero 2017 
cidad activa que, se entiende, han de vincular a un amplio número de sujetos entre los que se encuentran todas las Administraciones Públicas, los órganos del Poder Legislativo y Judicial en lo que se refiere a sus actividades sujetas a Derecho Administrativo» ${ }^{70}$. Por el contrario, para el profesor Sánchez de Diego, «habría sido más correcto configurar el derecho de acceso a la información pública como un derecho fundamental entroncado con las libertades informativas del artículo 20 de la Constitución Española. Este precepto ampara la existencia de una comunicación pública libre, esencial para que exista una auténtica opinión pública libre que es el fundamento de una sociedad democrática. El derecho de acceso presenta también esa dimensión pública» ${ }^{71}$.

La transparencia es un mantra política de mejora de la gestión pública, y evidentemente muchas cosas pueden ser mejorables en la ley española, pero como recuerda Emilio Guichot, «los estudios y el sentido común nos advierten de que no basta con tener una buena Ley. Si acudimos al último estudio internacional sobre calidad de las Leyes estatales de transparencia de más de cien países, nos encontraremos con el dato de que entre las diez mejores valoradas se encuentran, por ejemplo, las de Liberia, El Salvador o Sierra Leona, y entre las peor valoradas, las de Alemania, Austria, Bélgica o Italia. Cabe por lo menos dudar de que la práctica de la transparencia por la Administración — qué información se pone a disposición de todos en internet y si es verdadera y actualizada, cuál es el tiempo real de respuesta a las solicitudes (...), si se destinan suficientes recursos humanos cualificados a la aplicación de las leyes de transparencia (...) - sea acorde con estas valoraciones de la estructura normativa» ${ }^{72}$.

Para Guichot, cuatro son los problemas fundamentales a los que se enfrenta toda ley de transparencia y, en este caso, también la Ley 19/2013: Primero, una ley de transparencia es un instrumento útil para la prevención de la corrupción y la mejora del gobierno, pero no basta sin mecanismos efectivos de aplicación, voluntad de ponerlos en funcionamiento y una ciudadanía activa que ejerza y batalle por su derecho a saber. Segundo, la transparencia ha sido una necesidad fijada de abajo a arriba por los escándalos de corrupción, que han producido una gran desconfianza en la política y las instituciones, lo que pone en evidencia la falta de voluntad histórica por abordar este tema en nuestro país, a diferencia de los países de nuestro entorno, si bien la Ley aprobada en un sprint es plenamente homologable a las de nuestros vecinos europeos. Tercero, la ley española y las autonómicas tendrían un nivel de exigencia razonable, pero dejan un amplio margen de desarrollo normativo todavía y de interpretación aplicativa, de cuyo uso dependerá el nivel real de transparencia. Y cuarto, será necesario que las autoridades de control actúen de forma independiente, no sólo de derecho, sino de hecho, para que haya una auténtica transparencia ${ }^{73}$.

70 SANCHEZ DE DIEGO Y FERNÁNDEZ DE LA RIVA, Manuel, Iurisprudentia Elegans: Revista de Derecho Político e Historia Constitucional, n. ${ }^{0} 1,2014$, pp. $30-55$ (p. 36), disponible en http://www. iurisprudentiaelegans.es/imagenes/numeros/Transparencia $\% 20$ y $\% 20$ acceso $\% 20 a \% 201 a \% 20$ informacion $\% 20$ desde $\% 20$ una \%20perspectiva\%20constitucional.pdf Fecha de consulta: 5 febrero 2017

71 Ibidem, p. 13.

72 GUICHOT, Emilio, op.cit., pp. 92-93.

${ }^{73}$ GUICHOT, Emilio, op.cit., pp.89-106. 
La Ley 19/2013 establece que el Congreso de los Diputados, el Senado y las Asambleas Legislativas de las Comunidades Autónomas regularán en sus respectivos reglamentos la aplicación concreta de sus disposiciones. En consecuencia, las Comunidades Autónomas han aprobado un marco específico propio de regulación de la transparencia y buen gobierno, algunas antes incluso que la Ley estatal. En el caso de las Comunidades Autónomas cuyos Parlamentos serán objeto de análisis, debemos citar la siguiente normativa en: Galicia ${ }^{74}$ (Ley 1/2016, de 18 de enero, de Transparencia y Buen Gobierno); Navarra (Ley Foral 11/2012, de 21 de junio, de la Transparencia y del Gobierno Abierto) ${ }^{75}$, Cataluña (Ley Catalana 19/2014, de 29 de diciembre, de Transparencia, Acceso a la Información Pública y Buen Gobierno) ${ }^{76}$; las Islas Baleares (Ley 4/2011, de 31 de marzo, de la Buena Administración y del Buen Gobierno de las Illes Balears) ${ }^{77}$; y la Comunidad Valenciana (Ley 2/2015, de 2 de abril, de la Generalitat, de Transparencia, Buen Gobierno y Participación Ciudadana de la Comunitat Valenciana) ${ }^{78}$. El País Vasco sería la excepción, estando en tramitación un anteproyecto de ley sobre transparencia ${ }^{79}$. Dada la extensión del artículo no se entra aquí en detalle en el contenido de la referida normativa autonómica, si bien se pueden realizar algunas observaciones generales. La primera, la celeridad con la que se han ido aprobando estas normas, fruto del malestar de la ciudadanía ante la gestión de algunos políticos y administraciones autonómicas, como bien apuntaba Guichot. La segunda, la necesidad de profundizar (en unos casos) o de adelantarse (en otros) a lo establecido en la Ley estatal de Transparencia. Algunas leyes autonómicas se han centrado en exclusiva en la regulación de la transparencia, como es el caso de Andalucía, dejando, paradójicamente, para el futuro la regulación jurídica del bueno gobierno. El resto, como recuerda

${ }^{74}$ Ley 1/2016, de 18 de enero, de Transparencia y Buen gobierno, en http://www.boe.es/boe/ dias/2016/04/04/pdfs/BOE-A-2016-3190.pdf Fecha de consulta: 3 enero 2017

75 Ley Foral 11/2012, de 21 de junio, de la Transparencia y del Gobierno Abierto, en http://www. boe.es/buscar/act.php?id=BOE-A-2012-9370

${ }^{76}$ Ley Catalana 19/2014, de 29 de diciembre, de Transparencia, Acceso a la Información Pública y Buen Gobierno, en https://www.boe.es/diario_boe/txt.php?id=BOE-A-2015-470 Fecha de consulta: 3 enero 2017

77 Ley 4/2011, de 31 de marzo, de la Buena Administración y del Buen gobierno de las Illes Balears, en https://boe.es/boe/dias/2011/04/30/pdfs/BOE-A-2011-7709.pdf Fecha de consulta: 12 enero 2017

${ }^{78}$ Ley 2/2015, de 2 de abril, de la Generalitat, de Transparencia, Buen Gobierno y Participación Ciudadana de la Comunitat Valenciana, en https:/boe.es/buscar/pdf/2015/BOE-A-2015-4547consolidado.pdf Fecha de consulta: 5 febrero 2017

79 Véase Anteproyecto de Ley de Transparencia de la Comunidad Autónoma Vasca (en tramitación) en

http://www.euskadi.eus/gobierno-vasco/-/plan_programa_proyecto/ley-de-transparenciaparticipacion-ciudadana-y-buen-gobierno-del-sector-publico-vasco/ (Fecha de consulta: 3 enero 2017). Debe citarse en el caso vasco, no obstante, la aprobación de la Ley 2/2016, de 7 de abril, de Instituciones Locales de Euskadi, cuyo Título VI se denomina «Gobierno Abierto. Transparencia, Datos Abiertos y Participación Ciudadana». 
José Manuel Fernández Luque ${ }^{80}$, han regulado junto al objeto común de la transparencia, otros temas relacionados, como el buen gobierno (Islas Baleares, La Rioja, Cataluña, Comunitat Valenciana o Galicia), el gobierno abierto (Navarra o Extremadura) o la participación ciudadana (Murcia, Castilla y León, Aragón o Comunitat Valenciana).

El acceso a la información pública es fundamental a la luz de la normativa europea, nacional y autonómica y, como resulta obvio, dicho acceso se debe dar en la lengua oficial del Estado afectado en cada caso, léase la lengua castellana en España.

\section{LA PRAXIS DEL MULTIPARLAMENTARISMO EN EL CUMPLIMIENTO DEL ART. 3 CE, EL ART. 9CE Y EL ART. 12 DE LA LEY DE TRANSPARENCIA}

En el marco empírico de la investigación se han analizarán seis parlamentos autonómicos: 1) El Parlamento Vasco (Eusko Legebiltzarra) ${ }^{81}$; 2) el Parlamento Navarro (Nafarroako Parlamentua) ${ }^{82}$; 3) el Parlamento Catalán (Parlament de Catalunya) ${ }^{83}$; 4) el Parlamento Valenciano (Corts Valencianes) ${ }^{84}$; 5) el Parlamento de Baleares (Parlament de les Illes Balears) ${ }^{85}$; y 6) el Parlamento Gallego (Parlamento de Galicia $)^{86}$. Para clarificar la información que será objeto de estudio, recurriremos al portal de transparencia del Gobierno de España ${ }^{87}$, que clasifica la información pública en cuatro categorías ${ }^{88}$ :

1) Institucional (estructura, funciones, planes y objetivos, composición, altos cargos, relación de puestos de trabajo, retribuciones).

2) Normativa (normativa en vigor, normativa en elaboración, otras disposiciones)

${ }^{80}$ FERNANDEZ LUQUE, José Manuel, 2017, p.145, disponible en http://www.jacobea.edu.mx/ revista/numeros/numero12/6.Marco_legal_transparencia.\%20Jose_Manuel_Fernandez_Luque.pdf Fecha de consulta: 24 noviembre 2017

81 Véase web oficial http://www.legebiltzarra.eus/portal/es/web/eusko-legebiltzarra Fecha: 4 febrero 2017.

${ }^{82}$ Véase web oficial en http://www.parlamentodenavarra.es/ Fecha de consulta: 7 marzo 2017.

${ }^{83}$ Véase web oficial en http://www.parlament.cat/web/index.html Fecha de consulta: 4 febrero 2017.

84 http://www.cortsvalencianes.es/cs/Satellite/Layout/Page/1260974710668/Home.html?lang=es_ ES fecha: 7 marzo 2017.

85 Véase web oficial en http://www.parlamentib.es/Home/Default.aspx Fecha de consulta: 7 marzo 2017.

${ }^{86} \mathrm{Vid}$. http://www.parlamentodegalicia.com/sitios/web/default.aspx Fecha de consulta: 4 febrero 2017.

87 Vid. Portal de Transparencia del Gobierno de España en http://transparencia.gob.es/ transparencia/transparencia_Home/index/Derecho-de-acceso-a-la-informacion-publica.html Fecha de consulta: 4 febrero 2017.

88 Portal de Transparencia, Categorías de Información pública, http://transparencia.gob.es/ transparencia/transparencia_Home/index/categorias.html 4 febrero 2017. 
3) Contratos, subvenciones y bienes inmuebles (contratos, convenios, subvenciones, bienes).

4) Presupuestos, fiscalización e informes (presupuestos, ejecución presupuestaria, cuentas anuales, informes de auditoría, informes de fiscalización, información y estadísticas relevantes).

Partiendo de esta clasificación, se analizarán los contenidos de la página web oficial de los citados parlamentos autonómicos, desde una perspectiva sincrónica, a lo largo de los meses de enero, febrero y marzo de 2017. Desde un punto de vista metodológico, se abordará una metodología descriptiva y comparada. La medición cualitativa de las web oficiales atenderá al seguimiento de las siguientes variables:

1) Existencia de un portal web oficial en versión castellana y en la lengua cooficial. Se valorará si la traducción es íntegra o parcial.

2) Existencia de una sección/apartado de documentación en la web oficial, en lengua castellana y la lengua oficial para cada una de las cuatro categorías señaladas (información institucional; normativa; contratos, subvenciones y bienes inmuebles; y presupuestos, fiscalización e informes). Se valorará si la traducción es íntegra o parcial.

La comparación de las variables indicadas desvelará el grado de cumplimiento del artículo 3 CE, el artículo 9CE y las obligaciones en materia de transparencia, por parte de las cámaras regionales. En este caso, la hipótesis de referencia radica en que se produce un incumplimiento de la Ley de Transparencia y de los artículos 3CE y 9CE, porque los ciudadanos no pueden acceder del mismo modo a la información pública en español y en las lenguas cooficiales. Se barajan dos posibles causes de incumplimiento: 1) el perfil lingüístico de la población; y 2) el perfil nacionalista del grupo parlamentario que domina la cámara.

\subsection{Parlamento Vasco}

Los datos del perfil lingüístico más recientes ofrecidos por el servicio de estadística vasco (el Eustat), de 2011, revelan que, sobre una población aproximada de 2 millones de habitantes, 408.561 emplean el euskera como lengua materna, por lo que dos tercios de la población son castellano hablantes $(1.572 .038$ ) y una minoría considera a ambas lenguas como maternas (117.073 personas). Por provincias, Guipúzcoa es donde más se habla euskera, seguido de Vizcaya y a mucha distancia de Álava ${ }^{89}$.

${ }^{89}$ EUSTAT, «Población de la C.A. de Euskadi por ámbitos territoriales, lengua materna y lengua hablada en casa», 2011, en http://www.eustat.eus/elementos/ele0000400/ti_Poblacion_de_la_CA_de_ Euskadi_por_ambitos_territoriales_lengua_materna_y_lengua_hablada_en_casa/tb10000490_c. html\#axzz4XlBEmFrp Fecha de consulta: 4 febrero 2017. 
El Parlamento Vasco, pese a contar con un peso muy importante de grupos parlamentarios de corte nacionalista, entre los que se encuentra el Partido Nacionalista Vasco o Bildu, traduce sistemáticamente al español y al euskera la información pública que ofrece en su página web. De este modo, se cumple con todas las variables a medir:

- Información institucional: La información institucional es completa en su versión castellana y en euskera, por lo que los ciudadanos están informados sobre la organización del parlamento ${ }^{90}$, los parlamentarios ${ }^{91}$ y otras cuestiones institucionales.

- Normativa: toda la normativa, tanto la vigente ${ }^{92}$, como la que se encuentra en proceso de tramitación ${ }^{93}$ está en castellano y en euskera.

- Contratos, subvenciones y bienes inmuebles: la traducción es también íntegra y total en este apartado, abordando lo relativo al empleo público ${ }^{94}$, el perfil del contratante ${ }^{95}$, contratos otorgados ${ }^{96}$, etc.

- Presupuestos, fiscalización e informes: se ofrece una versión completa en ambas lenguas de cuestiones como la intervención general y asuntos económicos, los sistemas de información y otro tipo de estudios ${ }^{97}$.

\subsection{Parlamento Navarro}

El mapa sociolingüístico elaborado por el Gobierno de Navarra, en 2011, reflejan lo siguiente: "el conocimiento de euskera creció de 1991 a 2011, sobre todo entre los jóvenes y de forma desigual en las diferentes zonas lingüísticas. En la Zona Vascófona los que se dicen bilingües se mantienen en torno al $60 \%$ de la población; en la Zona Mixta la población que se declara bilingüe aumenta su porcentaje en estos 20 años del 5,8\% al 12,4\% y en la Zona no Vascófona hay un incremento desde el 0,8\% hasta el 3,8\%» ${ }^{98}$. El dato global de personas bilingües habría pasado así del 9'90\% en 1991 and

\footnotetext{
90 http://www.legebiltzarra.eus/portal/es/web/eusko-legebiltzarra/conoce-el-parlamento/atencionciudana Fecha de consulta: 4 febrero 2017.

91 http://www.legebiltzarra.eus/pfrm_cm_leyc2_sdw.html Fecha de consulta: 4 febrero 2017.

92 Véase la normativa vigente en http://www.legebiltzarra.eus/pfrm_cm_leyc2_sdw.html Fecha de consulta: 4 febrero 2017.

93 http://www.legebiltzarra.eus/c_recientes.html Fecha de consulta: 4 febrero 2017.

94 http://www.legebiltzarra.eus/oposic/c_oposic_0.html Fecha de consulta: 4 febrero 2017.

95 http://www.legebiltzarra.eus/licita/c_licita_0.html Fecha de consulta: 4 febrero 2017.

96 http://www.legebiltzarra.eus/licita/c_licita_1.html Fecha de consulta: 4 febrero 2017.

97 http://www.legebiltzarra.eus/portal/es/web/eusko-legebiltzarra/servicios-administrativos/ organigrama

98 GOBIERNO DE NAVARRA, Mapa sociolongüístico de Navarra, 2011, en http://www. euskarabidea.es/fitxategiak/dokumentuak/testuak/mapa-sociolinguistico-2011_informe-2.pdf Fecha de consulta: 7 de marzo de 2017.
} 
$13^{\prime} 68 \%$ en $2001^{99}$. Este incremento en el uso del euskera es fruto del esfuerzo de la Comunidad Autónoma por incluir el estudio de la lengua en el sistema educativo, a través del Decreto Foral 159/1988, de 19 de mayo, que formalizó la incorporación del vascuence en la enseñanza no universitaria de Navarra. En conjunto, la competencia lingüística en euskera ha mejorado, pero la mayor parte de la población sigue siendo castellano parlante. El informe refleja cómo «la población bilingüe ha aumentado un 3,78\%, el incremento de los bilingües pasivos ba sido de 5,8 puntos y el porcentaje de la población clasificada como no vascófona ha descendido en 8,52 puntos porcentuales» ${ }^{100}$.

El Parlamento de Navarra ofrece información en castellano, euskera, inglés, francés y alemán, con objeto de dotarse de mayor visibilidad internacional. Como ocurría en el Parlamento Vasco, toda la información está íntegramente disponible en castellano, pese a contar con un peso creciente de grupos parlamentarios de corte nacionalista ${ }^{101}$. De este modo, se cumple con todas las variables a medir:

- Información institucional: se ofrecen todos los apartados traducidos, relativos a la historia ${ }^{102}$, funciones ${ }^{103}$, y organización del parlamento ${ }^{104}$; los parlamentarios (fichas personales, órganos, etc. ${ }^{105}$ y las cuestiones relativas a la presidenta de la Cámara y sus actividades ${ }^{106}$.

- Normativa: toda la normativa, tanto la vigente ${ }^{107}$, como la que se encuentra en proceso de tramitación ${ }^{108}$ y el calendario de sesiones ${ }^{109}$ están traducidos al castellano.

99 Ibidem, p. 16.

100 Fuente: GOBIERNO DE NAVARRA, Mapa sociolongüistico de Navarra, 2011, p. 16 en http:// www.euskarabidea.es/fitxategiak/dokumentuak/testuak/mapa-sociolinguistico-2011_informe-2.pdf Fecha de consulta: 7 de marzo de 2017.

101 En las elecciones legislativas de 2015, Geroa Bai y EH Bildu obtuvieron 9 y 8 escaños, respectivamente (obteniendo así un escaño más cada uno, respecto a las elecciones de 2011). El resto de formaciones tuvieron la siguiente representación en 2015: Unión del Pueblo Navarro (15), Partido Socialista (7), Podemos (7), Partido Popular(2) e Izquierda Unida-Ezquerra (2). Fuente: http://www. elecciones2015.navarra.es/13pdf/C13-COMP_L1.pdf Fecha de consulta: 7 marzo 2017.

102 http://www.parlamentodenavarra.es/es/contenido/referencia-hist $\% \mathrm{C} 3 \% \mathrm{~B} 3$ rica

$103 \mathrm{http}: / /$ www.parlamentodenavarra.es/es/contenido/funciones-de-la-c\%C3\%A1 mara-legislativa

$104 \mathrm{http} / / /$ www.parlamentodenavarra.es/es/composicion-organos/parlamentarios-forales

105 http://www.parlamentodenavarra.es/es/composicion-organos/parlamentarios-forales Fecha de consulta: 7 marzo 2017.

106 http://www.parlamentodenavarra.es/contenido/saludo-de-la-presidenta Fecha de consulta: 7 marzo 2017.

107 http://www.parlamentodenavarra.es/comunicacion/leyes-forales Fecha de consulta: 7 marzo 2017.

108 http://www.parlamentodenavarra.es/es/actividad-parlamentaria/iniciativas-tramitacion Fecha de consulta: 7 marzo 2017.

109 http://www.parlamentodenavarra.es/es/actividad-parlamentaria/calendario-de-sesiones Fecha de consulta: 7 marzo 2017. 
- Contratos ${ }^{110}$, subvenciones ${ }^{111}$ y bienes inmuebles ${ }^{112}$ : la traducción es también íntegra y total en este apartado, abordando lo relativo al empleo público, el perfil del contratante, contratos otorgados, etc.

- Presupuestos ${ }^{113}$, fiscalización e informes ${ }^{114}$ : se ofrece una traducción completa de cuestiones como la intervención general y asuntos económicos, los sistemas de información y otro tipo de estudios.

Hay que recordar, en este caso, que tras las elecciones legislativas de 2015, aunque Unión del Pueblo Navarro era el partido con mayor número de parlamentarios, fue un histórico acuerdo entre Geroa Bai, EH Bildu, Podemos e Izquierda-Ezkerra, el que permitió formar gobierno. El nuevo pacto no ha supuesto, sin embargo, una merma en el acceso a la documentación en castellano para los navarros, aunque sí ha dado lugar a la aprobación del I Plan Estratégico del Euskera (2016$2019)^{115}$, bajo la premisa de la necesidad de fomentar el euskera en la administración y en la oferta educativa.

\subsection{Parlamento Gallego}

Desde el punto de vista de la población, el Consello da Cultura Galega estima que, en Galicia, 2 millones de personas hablan gallego como primera lengua y otro medio millón lo usa como segunda lengua ${ }^{116}$. Los datos estadísticos de conocimiento del gallego, ofrecidos por el Instituto Galego de Estadística ${ }^{117}$ revelan, para el año 2013, unos índices muy elevados de conocimiento de la lengua: más de la mitad de los gallegos (57’3\%) tiene mucho conocimiento del gallego y casi un 30\% tiene bastante conocimiento, lo que supone que más del $80 \%$ emplea el gallego como lengua habitual. Asimismo, el $82 \%$ de los hablantes ha aprendido la lengua en el entorno

110 http://www.parlamentodenavarra.es/contenido/contrataciones-en-curso Fecha de consulta: 7 marzo 2017.

111 http://www.parlamentodenavarra.es/es/contenido/subvenciones-de-los-grupos-parlamentarios Fecha de consulta: 7 marzo 2017.

112 http://www.parlamentodenavarra.es/es/contenido/inventario-inmuebles-veh\%C3\% ADculosm\%C3\%B3viles-otros-1 Fecha de consulta: 7 marzo 2017.

113 http://www.parlamentodenavarra.es/es/transparencia/presupuestos-y-cuentas Fecha de consulta: 7 marzo 2017.

114 http://www.parlamentodenavarra.es/es/contenido/informes-jur\%C3\%ADdicos

115 El I Plan Estratégico del euskera fue aprobado por el Gobierno de Navarra en enero de 2017. Véase https://www.navarra.es/home_es/Actualidad/Sala+de+prensa/Noticias/2017/01/25/ Aprobado $+\mathrm{el}+\mathrm{I}+$ Plan + Estrategico + del + Euskera.htm

116 CONSELLO DA CULTURA GALEGA, «Número de hablantes», en http://consellodacultura. gal/cdsg/loia/ficha.php? idioma=3\&seccion=5 Fecha de consulta: 4 febrero 2017.

117 INSTITUTO GALEGO DE ESTADÍSTICA, «Coñecemento do Galego», 2013, https://www. ige.eu/estatico/estat.jsp? ruta $=\mathrm{html} / \mathrm{gl} / \mathrm{ecv} / \mathrm{ECV} \_$ResumoResultados_galego.html Fecha de consulta: 4 febrero 2017. 
familiar, y no en la escuela o a través de otros medios, lo que refuerza el carácter del gallego como lengua materna.

En el Parlamento de Galicia, cuyo grupo mayoritario es el Partido Popular, la información que se ofrece en gallego y castellano parece, a priori, la misma, ya que los títulos de los apartados se traducen indistintamente en uno y otro idioma. Sin embargo, al abrir los contenidos de cada apartado surge la sorpresa de que el ciudadano no tiene acceso por igual en castellano y gallego a la información. La preferencia por el gallego se percibe, por ejemplo, en los discursos del presidente de la cámara, el reglamento de la Cámara ${ }^{118}$, los acuerdos del Parlamento, el orden del día ${ }^{119}$, y un largo etcétera. Del mismo modo, hay una advertencia previa en la página de inicio en castellano, que alerta sobre lo siguiente: «La versión en castellano es una traducción automática. Si encuentra algún fallo, por favor, envíenoslo a:tradutor@parlamentodegalicia.es» ${ }^{120}$. Ello significa, por un lado, que la lengua preferente de trabajo es el gallego y, por otro, que se puede plantear algún problema puntual en la traducción, al haberse optado por una herramienta informática de traducción (ya sea por motivos económicos, políticos o incluso de rapidez en la traducción).

Por consiguiente, la información en castellano es parcial. Se traducen el grueso de los apartados fijos de la web, pero no aquellos relativos a la actividad diaria del Parlamento o a su propia reglamentación interna. De este modo, en castellano, contamos con la siguiente información: 1) Actividad Parlamentaria (noticias de visitas, reuniones, etc.); 2) información Parlamentaria; 3) los órganos del Parlamento de Galicia ${ }^{121}$; 4) el sistema de trabajo y de decisión ${ }^{122}$; 5) la función y las competencias legislativas del Parlamento ${ }^{123}$; 6) los procedimientos legislativos del Parlamento ${ }^{124}$; 7) las funciones de creación, control e impulso de la acción política del Parlamento de Galicia ${ }^{125}$; 8) la función electiva ${ }^{126}$; 9) los procedimientos de la

118 Véase como ejemplo http://www.es.parlamentodegalicia.es/sitios/web/BibliotecaInfInstitucional/ Regulamento_consolidado_2015.pdf Fecha de consulta: 4 febrero 2017.

119 Véase como ejemplo http://www.es.parlamentodegalicia.es/sitios/web/AxendaParlamentaria/ pc_2017_01_25_convo.pdf Fecha de consulta: 4 febrero 2017.

${ }_{120}$ Fuente: http://www.es.parlamentodegalicia.es/sitios/web/default.aspx Fecha de consulta: 4 febrero 2017.

121 http://www.es.parlamentodegalicia.es/sitios/web/contenidogal/InformacionInstitucional/ Organizacion.aspx\#s10 Fecha de consulta: 4 febrero 2017.

$122 \mathrm{http} / /$ www.es.parlamentodegalicia.es/sitios/web/contenidogal/InformacionInstitucional/ Organizacion.aspx\#s20 Fecha de consulta: 4 febrero 2017.

$123 \mathrm{http} / /$ www.es.parlamentodegalicia.es/sitios/web/contenidogal/InformacionInstitucional/ Organizacion.aspx\#s30 Fecha de consulta: 4 febrero 2017.

124 http://www.es.parlamentodegalicia.es/sitios/web/contenidogal/InformacionInstitucional/ Organizacion.aspx\#s40 Fecha de consulta: 4 febrero 2017.

$125 \mathrm{http} / /$ www.es.parlamentodegalicia.es/sitios/web/contenidogal/InformacionInstitucional/ Organizacion.aspx\#s50 Fecha de consulta: 4 febrero 2017.

126 http://www.es.parlamentodegalicia.es/sitios/web/contenidogal/InformacionInstitucional/ Organizacion.aspx\#s60 Fecha de consulta: 4 febrero 2017. 
relación con los órganos estatales ${ }^{127}$; y 10) la publicidad y el conocimiento del Parlamento ${ }^{128}$.

Por el contrario, quedan muchas cuestiones sin traducir, entre ellas, las vinculadas al apartado "participación ciudadana», «transparencia», «normativa» o documentos de interés (presupuestos; memorias de control; memorias de fiscalización, informes económicos, contratación administrativa, procedimientos selectivos, becas, etc.). A este respecto, resulta preocupante que la información publicada en el Boletín Oficial y en el Diario de Sesiones aparezca exclusivamente en gallego. Véase como ejemplo la Lei 7/2015, do 7 de agosto, de iniciativa lexislativa popular e participación cidadá no Parlamento de Galicia ${ }^{129}$.

\subsection{Parlamento Catalán}

Respecto a los datos de hablantes, el propio instituto oficial de estadística catalán (Institut de Estadística de Catalunya), no tiene información en español, solo en catalán e inglés. Las cifras revelan que el 95’12\% de la población entiende catalán, 73’16\% lo habla y un $55^{\prime} 70 \%$ lo escribe ${ }^{130}$, por lo que también el parlamento autonómico incumple su obligación de ofrecer tanto en catalán como español la información.

En el Parlamento Catalán, dominado por grupos nacionalistas, el portal web da prioridad al catalán, lengua en la que aparecen todos los contenidos que recoge dicha plataforma. Aparece también una opción para obtener información del Parlament en castellano y en occitano, pero los contenidos no son globales. La propia web así lo advierte $^{131}$, el portal señala que pueden consultarse en occitano - aranés - y castellano: 1) La información institucional relativa a la historia, la estructura y el funcionamiento del Parlamento; 2) los textos legislativos (leyes) aprobadas; y 3) las publicaciones oficiales del Parlamento, en cuanto a que se traducen los documentos originales presentados en el Registro en cualquiera de las lenguas oficiales en Cataluña, en el caso del Butlletí Oficial del Parlament de Catalunya (BOPC), y las intervenciones de los oradores en las sesiones parlamentarias, sea cual sea la lengua oficial en que se hayan expresado, en el caso del Diari de Sessions del Parlament de Catalunya (DSPC).

El resto de la información, como, por ejemplo, documentos jurídicos de diversa índole, informes, concursos, oposiciones, contrataciones, la agenda de la Cámara, etc.

127 http://www.es.parlamentodegalicia.es/sitios/web/contenidogal/InformacionInstitucional/ Organizacion.aspx\#s70 Fecha de consulta: 4 febrero 2017.

128 http://www.es.parlamentodegalicia.es/sitios/web/contenidogal/InformacionInstitucional/ Organizacion.aspx\#s80 Fecha de consulta: 4 febrero 2017.

129 Véase como ejemplo la LEI 7/2015, do 7 de agosto, de iniciativa lexislativa popular e participación cidadá no Parlamento de Galicia, en http://www.es.parlamentodegalicia.es/sitios/web/ BibliotecaLeisdeGalicia/Lei7_2015.pdf\#page=3

${ }^{130} \mathrm{http}: / / \mathrm{www}$.idescat.cat/economia/inec?tc=3\&id=da04 Fecha de consulta: 4 febrero 2017.

131 Véase http://www.parlament.cat/web/serveis/idioma/index.html\#castellano Fecha de consulta: 4 febrero 2017. 
no está traducido, de modo que la web del Parlament remite al usuario a la herramienta informática Google Translate, con la siguiente advertencia: «Esta herramienta facilita la traducción automática del resto de contenidos del web. El Parlamento no se hace responsable de las versiones obtenidas, que no tienen carácter oficial» ${ }^{132}$.

\subsection{Parlamento Balear}

El perfil lingüístico de la ciudadanía es claramente catalán. El Consell de Mallor$\mathrm{ca}^{133}$ remite a la encuesta de usos lingüísticos de 2007, elaborada por la Asociación de Lingüistas de la Lengua Catalana ${ }^{134}$. En dicha encuesta, los datos muestran que la capacidad de entender el catalán sería la siguiente: Cataluña (97’4\%), Andorra (96\%), Baleares (93'1\%). La capacidad de lectura es también muy notable: Cataluña (90'5\%), Andorra (89'7\%), Baleares (79'6\%). La capacidad de hablar el catalán sería un poco inferior, pero sigue siendo generalizada, tanto en Cataluña (84'7\%), como en Andorra $\left(78^{\prime} 9 \%\right)$ y Baleares $\left(74{ }^{\prime} 6 \%\right)$. Mientras, la escritura sería la habilidad que presenta mayor dificultad. Escriben en catalán, el 62’3\% de los catalanes, el 61'1\% de los andorranos, y el $46^{\prime} 9 \%$ de los ciudadanos de las Baleares ${ }^{135}$.

El Parlament de les Illes Balears presenta multitud de irregularidades, respecto a la información pública ofrecida en castellano. La primera cuestión que llama la atención es la ubicación del icono donde se escoge el idioma en el que se ofrece la información. En todas las webs de los parlamentos autonómicos consultados el icono del idioma aparece en la parte superior derecha, al acceder al portal de presentación. Ello es una práctica habitual en las webs institucionales en multitud de países y en organismos públicos, tanto nacionales como internacionales. En el caso balear, sin embargo, la opción del idioma en castellano está en la parte inferior, de modo que no es rápida e intuitiva la búsqueda del citado apartado. Una vez escogido el idioma castellano ${ }^{136}$, la web tampoco aparece traducida en su totalidad: la portada incluye unas noticias, con carácter preferente, en catalán.

La información institucional relativa al Parlamento ${ }^{137}$ también está en catalán. Ello incluye datos relativos a: grupos parlamentarios y su composición ${ }^{138}$, la agenda

\footnotetext{
132 Ibidem

133 http://www.conselldemallorca.net/?\&id_parent=316\&id_class $=1851 \&$ id_section $=1852 \&$ id_ son=2238\&id_grandson=3020 Fecha: 7 marzo 2017.

134 ASSOCIACIO DE SOCIOLINGÜISTES DE LLENGUA CATALANA, La situació sociolingüirstica als territoris de parla catalana a l'inici del segle XXI. L'Alguer, Andorra, Catalunya, Catalunya del Nord, la Franja, les Illes Balears $i$ el País Valencià, 2007, en http://www.ub.edu/slc/socio/situacioactualcatala.pdf Fecha: 7 marzo 2017.

135 Ibidem, p. 2

${ }^{136}$ Versión en castellano de la web http://www.parlamentib.es/Home/Default.aspx Fecha: 7 marzo 2017.

137 http://www.parlamentib.es/Home/Default.aspx Fecha de consulta: 7 marzo 2017.

$138 \mathrm{http} / / /$ contingutsweb.parlamentib.es/comunicacio/9/Hemicicle2015.pdf Fecha: 7 marzo 2017.
} 
y actividad parlamentaria ${ }^{139}$, las noticias de actualidad ${ }^{140}$ y otros. En este apartado institucional, tan solo se puede acceder en lengua castellana a la información relativa a la sede (ubicación ${ }^{141}$, historia ${ }^{142}$ ), una breve explicación de lo que son formalmente

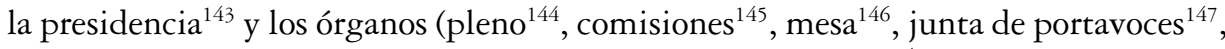
etc.) de la cámara, un listado de la sucesión de legislaturas ${ }^{148}$, y las funciones del Parlament ${ }^{149}$.

La información legislativa, tanto de las legislaturas pasadas, como de la legislatura actual se presentan igualmente en catalán, independientemente de que estén aprobadas o en proceso de tramitación, como ocurre con otros documentos de importancia jurídica y/o política. De forma específica, figuran en catalán: el Estatuto de Autonomía $^{150}$, la Ley Electoral autonómica ${ }^{151}$, las resoluciones de la Presidencia ${ }^{152}$, la legislación autonómica ${ }^{153}$ y los decretos ${ }^{154}$, el acceso al Boletín Oficial del Parlamento $^{155}$, los diarios de sesiones ${ }^{156}$, las preguntas parlamentarias ${ }^{157}$ y las declaraciones institucionales ${ }^{158}$.

Por el contrario, se puede acceder en lengua castellana a los contenidos del Boletín Oficial de las Islas Baleares (Butlletí Oficial de les Illes Balears) ${ }^{159}$, al Reglamento del Parlament ${ }^{160}$, a la explicación del procedimiento de la tramitación legislativa ${ }^{161}$ y, como resulta obvio, a la Constitución española y la legislación estatal ${ }^{162}$.

\footnotetext{
139 http://www.parlamentib.es/Agenda/Agenda.aspx Fecha: 7 marzo 2017.

140 http://www.parlamentib.es/webdocs/NoticiesPIB.aspx Fecha: 7 marzo 2017.

141 http://www.parlamentib.es/PageHandler/La_Seu Fecha: 7 marzo 2017.

142 http://www.parlamentib.es/PageHandler/Historia Fecha: 7 marzo 2017.

143 http://www.parlamentib.es/PageHandler/Presidencia Fecha: 7 marzo 2017.

144 http://www.parlamentib.es/Representants/Ple.aspx Fecha: 7 marzo 2017.

145 http://www.parlamentib.es/Representants/Comissions.aspx Fecha: 7 marzo 2017.

146 http://www.parlamentib.es/Representants/Mesa.aspx Fecha: 7 marzo 2017.

147 http://www.parlamentib.es/Representants/JuntaPortaveus.aspx Fecha: 7 marzo 2017.

148 http://www.parlamentib.es/PageHandler/Legislatures Fecha: 7 marzo 2017.

149 http://www.parlamentib.es/PageHandler/Que_Es Fecha: 7 marzo 2017.

150 http://web.parlamentib.es/RecursosWeb/DOCS/EstatutAutonomiaIB.pdf Fecha: 7 marzo 2017.

151 http://web.parlamentib.es/recursosweb/docs/llei_electoral_caib.pdf Fecha: 7 marzo 2017.

152 http://web.parlamentib.es/repositori/PUBLICACIONS/8/bopibs/bopib-08-024.pdf\#page=53
}

Fecha: 7 marzo 2017.

153 http://www.parlamentib.es/Lleis/LleisLegisPIB.aspx?legis=8 Fecha: 7 marzo 2017.

154 http://www.parlamentib.es/Lleis/LleisPIB.aspx?tipus=DLEX Fecha: 7 marzo 2017.

155 http://web.parlamentib.es/repositori/PUBLICACIONS/9/bopibs/bopib-09-086.pdf Fecha: 7 marzo 2017.

156 http://www.parlamentib.es/Publicacions/DiarisSessions.aspx Fecha: 7 marzo 2017.

157 http://www.parlamentib.es/Actividad/InterpelPreguntesPle.aspx Fecha: 7 marzo 2017.

158 http://www.parlamentib.es/Publicacions/DeclaracionsInst.aspx Fecha: 7 marzo 2017.

159 http://www.caib.es/eboibfront/es/2017/10624 Fecha: 7 marzo 2017.

160 http://contingutsweb.parlamentib.es/Publica/7/altres/ReglamentPIB_es.pdf Fecha: 7 marzo 2017.

161 http://www.parlamentib.es/PageHandler/Activitat_Parlamentaria?redir=1 Fecha: 7 marzo 2017.

162 http://www.parlamentib.es/PageHandler/Legis_Estat_Autonomia Fecha: 7 marzo 2017. 
Respecto a los contratos ${ }^{163}$, subvenciones ${ }^{164}$ y bienes inmuebles ${ }^{165}$, debe añadirse que la traducción al castellano también es inexistente. Los datos que se ofrecen son amplios, abordando lo relativo al empleo público, el perfil del contratante, contratos otorgados, etc., pero están en catalán.

Igualmente, en relación a los presupuestos ${ }^{166}$, fiscalización e informes ${ }^{167}$, conviene señalar que tampoco se ofrece una traducción de cuestiones como la intervención general y asuntos económicos, los sistemas de información y otro tipo de estudios.

Desde la perspectiva política, el Partido predominante en la Cámara es un partido de ámbito nacional, el Partido Popular (con 20 escaños), seguido del Partido Socialista (14 escaños) y de Podemos (10 escaños). Como ha sucedido en otras Comunidades, tras las elecciones autonómicas de 2015, se produjo un pacto, de modo que el Partido Socialista preside el Gobierno, con el apoyo de Podemos y la formación econacionalista Mes (Mes por Mallorca y Mes por Menorca), siendo otorgada a cambio la Presidencia del Parlamento a Podemos. A este respecto, se percibe un cambio importante, en cuanto al tema lingüístico, ya que la información accesible del Parlamento Balear que corresponde a las pasadas legislaturas (cuando el Partido Popular ostentaba la mayoría parlamentaria y el gobierno) se encuentra en castellano. Este es el caso de los datos, por ejemplo, de la legislatura 2007-2011, relativos a la normativa aprobada ${ }^{168}$, el listado de diputa$\operatorname{dos}^{169}$, sus grupos parlamentarios ${ }^{170}$, o la composición de los órganos ${ }^{171}$.

\subsection{Parlamento Valenciano}

Los datos de 2015 del fondo estadístico y documental de la Generalitat Valenciana $^{172}$ revelan el siguiente mapa sociolingüístico: el $44 \%$ de la población entiende perfectamente el valenciano (aunque sólo un 33\% lo habla perfectamente, un $28 \%$ lo lee perfectamente y un $20 \%$ lo escribe perfectamente). En el lado opuesto de la balanza se sitúa en torno al $27 \%$ de la población que lo entiende poco o nada; un $48 \%$ que lo habla poco o nada; un $47 \%$ que lee poco o nada en valenciano; y un $64 \%$ que escribe poco o nada en dicha lengua ${ }^{173}$. Esto es, aunque hay un conocimiento bastan-

163 http://www.parlamentib.es/PageHandler/Contractes Fecha: 7 marzo 2017.

164 http://www.parlamentib.es/PageHandler/Convenis_Subvencions Fecha: 7 marzo 2017.

165 http://www.parlamentib.es/PageHandler/Info_Patrimoni Fecha: 7 marzo 2017.

166 http://www.parlamentib.es/PageHandler/Info_Compt_Pressup Fecha: 7 marzo 2017.

167 http://www.parlamentib.es/PageHandler/Assessories_Informes_Externs Fecha: 7 marzo 2017.

168 http://www.parlamentib.es/Lleis/LleisLegisPIB.aspx?legis=7 Fecha: 7 marzo 2017.

169 http://contingutsweb.parlamentib.es/protocol/7/7_diputats_senadors_castella.pdf Fecha: 7 marzo 2017.

${ }^{170}$ http://contingutsweb.parlamentib.es/protocol/7/7_ggpp_castella.pdf Fecha: 7 marzo 2017.

171 http://contingutsweb.parlamentib.es/protocol/7/7_organs_castella.pdf Fecha: 7 marzo 2017.

172 GENERALITAT VALENCIANA, Conocimiento y uso social del valenciano. Encuesta 2015, 2016, en file://C:/Users/Ainhoa/Downloads/encuesta \%20uso\%20valenciano\%202015\%20espa\%C3\%B1ol. pdf y http://www.ceice.gva.es/web/fondo-estadistico-documental Fecha de consulta: 7 marzo 2017

173 Ibidem, p. 6. 
te generalizado del valenciano, cerca de la mitad de la población no maneja dicha lengua, por lo que el parlamento autonómico cumple con el artículo 3CE.

Las Corts Valencianes presentan el icono del idioma (español-inglés) en la parte superior de la web, como sucede con todos los parlamentos autonómicos analizados, a excepción del balear. Las Corts traducen sistemáticamente al español y al valenciano la información pública en su página web, referida a:

- Información institucional ${ }^{174}$ : se ofrecen todos los apartados traducidos, relativos a la organización del parlamento; los parlamentarios (fichas personales, órganos, etc.), su actividad diaria ${ }^{175}$, etc.

- Normativa: toda la normativa, tanto la vigente ${ }^{176}$, como la que se encuentra en proceso de tramitación (ya sean proyectos de ley ${ }^{177}$ o proposiciones de ley ${ }^{178}$ ) está en castellano.

- Contratos, subvenciones y bienes inmuebles ${ }^{179}$ : la versión castellana es también íntegra y total en este apartado, abordando lo relativo al empleo público, el perfil del contratante, contratos otorgados, etc.

— Presupuestos, fiscalización e informes ${ }^{180}$ : se ofrece una versión completa en castellano de cuestiones como la intervención general y asuntos económicos, los sistemas de información y otro tipo de estudios.

El partido con más escaños es el Partido Popular (31), seguido del Partido Socialista (23), Compromís (19), Ciudadanos (13), Podemos (13). En este caso, como ocurría en otras Comunidades el PP perdió el control del gobierno en 2015, tras el acuerdo histórico entre el PSOE, Compromís y Podemos. Este hecho no ha generado, sin embargo, un problema lingüístico, en lo que a las Cortes Valencianas se refiere, por las razones socio-lingüísticas ya analizadas, donde el perfil mayoritario es castellano-hablante.

\subsection{Análisis autonómico comparado}

A la luz de los datos obtenidos se puede concluir que el cumplimiento de los artículos 3 y 9CE, y del art. 12 de la Ley 19/2013 es parcial, en el marco del multi-

\footnotetext{
${ }^{174}$ http://www.cortsvalencianes.es/cs/Satellite/Layout/Page/1260974710698/QueSon.html?lang=es_ES

175 http://www.cortsvalencianes.es/cs/Satellite/Layout/Page/1260974710705/QueHacen.html?lang=es_ES

176 http://www.cortsvalencianes.es/cs/Satellite/Layout/Page/1260974740185/LeyesAprobadas. html?lang=es_ES Fecha de consulta: 7 marzo 2017

177 http://www.cortsvalencianes.es/cs/Satellite/Layout/Page/1260974742394/Proyectoley. html?lang=es_ES Fecha de consulta: 7 marzo 2017

178 http://www.cortsvalencianes.es/cs/Satellite/Layout/Page/1260974742398/Proposicionley. html?lang=es_ES Fecha de consulta: 7 marzo 2017

179 http://www.cortsvalencianes.es/cs/Satellite/Layout/Page/1260974712787/LasCortesinforman. html?lang=es_ES Fecha de consulta: 7 marzo 2017

180 http://www.sindicom.gva.es/web/wdweb.nsf/menu/informes
} 
parlamentarismo autonómico. Los resultados se muestran de forma comparada en la siguiente tabla.

Tabla 1. Uso de las lenguas en el portal web oficial de los parlamentos autonómicos del País Vasco, Navarra, Galicia, Cataluña, Baleares y la Comunidad Valenciana. Enero-Marzo 2017

\begin{tabular}{|c|c|c|c|c|c|c|c|c|}
\hline \multirow[b]{2}{*}{$\begin{array}{l}\text { Parlamento } \\
\text { Autonómico }\end{array}$} & \multicolumn{2}{|c|}{$\begin{array}{l}\text { Información } \\
\text { Institucional } \\
\text { VERSIÓN EN } \\
\text { CASTELLANO }\end{array}$} & \multicolumn{2}{|c|}{$\begin{array}{l}\text { Información } \\
\text { Normativa } \\
\text { VERSIÓN EN } \\
\text { CASTELLANO }\end{array}$} & \multicolumn{2}{|c|}{$\begin{array}{l}\text { Información de } \\
\text { Contratos y otros } \\
\text { VERSIÓN EN } \\
\text { CASTELLANO }\end{array}$} & \multicolumn{2}{|c|}{$\begin{array}{l}\text { Información de } \\
\text { Presupuesto y otros } \\
\text { VERSIÓN EN } \\
\text { CASTELLANO }\end{array}$} \\
\hline & Íntegra & $\begin{array}{c}\text { Parcial } \\
\text { y/o nula }\end{array}$ & Íntegra & $\begin{array}{c}\text { Parcial } \\
\text { y/o nula }\end{array}$ & Íntegra & $\begin{array}{c}\text { Parcial } \\
\text { y/o nula }\end{array}$ & Íntegra & $\begin{array}{l}\text { Parcial } \\
\text { y/o nula }\end{array}$ \\
\hline País Vasco & $\mathrm{X}$ & & $\mathrm{X}$ & & $\mathrm{X}$ & & $\mathrm{X}$ & \\
\hline Navarra & $\mathrm{X}$ & & $\mathrm{X}$ & & $\mathrm{X}$ & & $\mathrm{X}$ & \\
\hline Galicia & & $\mathrm{X}$ & & $\mathrm{X}$ & & $\mathrm{X}$ & & $\mathrm{X}$ \\
\hline Cataluña & & $\mathrm{x}$ & & $\mathrm{X}$ & & $\mathrm{x}$ & & $\mathrm{X}$ \\
\hline Baleares & & $\mathrm{X}$ & & $\mathrm{X}$ & & $\mathrm{X}$ & & $\mathrm{X}$ \\
\hline C.Valenc. & $\mathrm{X}$ & & $\mathrm{X}$ & & $\mathrm{X}$ & & $\mathrm{X}$ & \\
\hline
\end{tabular}

Fuente: Elaboración propia.

Los parlamentos autonómicos que cumplen con sus obligaciones, en lo que se refiere a la lengua castellana, son: el Parlamento Vasco, el Navarro, y el Valenciano. Por el contrario, suspenden el Parlamento de Galicia, el de Cataluña y el de Baleares. La razón explicativa en todos los casos, como se ha visto, es el grado de bilingüismo de los ciudadanos y no así el color del partido dominante en el legislativo autonómico.

\section{CONCLUSIONES}

El artículo 3 CE establece que no cabe un monolingüismo en España, ni en ninguna de las partes del territorio español. Del apartado 3 del artículo 3 CE se deducen dos consecuencias jurídicas: La primera se refiere a la obligación de proteger de forma activa el conjunto de las lenguas de España, esto es, tanto el castellano como las demás lenguas españolas, a cuyo servicio se consagran los apartados 1 y 2 del artículo 3 CE. La segunda implica que también hay que proteger las demás modalidades lingüísticas, aunque no alcancen la denominación de lenguas oficiales, puesto que la suma de todas ellas forma parte del patrimonio cultural común. A la luz de los datos obtenidos en el estudio de caso se pueden extraer las siguientes conclusiones: 
Primera. El deber de los españoles de conocer el castellano hace suponer que ese conocimiento existe. Del mismo modo, el reconocimiento de la oficialidad del castellano hace suponer que los ciudadanos tienen acceso a la normativa generada en las Cámaras autonómicas y a otro tipo de información pública en castellano. Sin embargo, los datos muestran que ello no se produce en todos los casos estudiados. El Parlamento Vasco, el Navarro, y el Valenciano cumplen con sus obligaciones lingüísticas, mientras que se detectan deficiencias en los otros casos analizados: Cataluña, Galicia y las Islas Baleares.

Segunda. Las causas del incumplimiento detectado son muy diversas. Se puede apuntar que no existe relación entre el incumplimiento de la Ley de Transparencia y el artículo 3CE y el «color» del partido político mayoritario en la cámara autonómica. El incumplimiento, por tanto, puede provenir tanto de partidos cuya ideología es nacionalista, como de partidos de ámbito nacional, independientemente de su ubicación ideológica en una escala izquierda-derecha. Por el contrario, el incumplimiento parece estar relacionado con el volumen de hablantes de la lengua cooficial del territorio. De modo que se puede establecer una relación directa: a mayor conocimiento de la lengua cooficial, mayor incumplimiento (y menor acceso a la documentación en español) y viceversa.

Tercera. El reconocimiento del plurilingüismo es complejo, en la medida en que el artículo $3 \mathrm{CE}$ entronca con numerosas materias, entre ellas, las relativas a los artícu$\operatorname{los} 1,2,10.1,14,23.2,27,46,139,147,148.1 .17,149$ y la disposición final de nuestra Constitución. La protección y promoción de una lengua afecta a muchos derechos básicos relacionados directamente con la personalidad y el desarrollo del ser humano. Prueba de ello es que no son las lenguas o los territorios quienes tienen el derecho de elegir su lengua vehicular, sino que son las personas quienes tienen el derecho a elegir en qué lengua desean expresarse o relacionarse con los demás, ya sean entes públicos o privados. Más aún, las lenguas no son sólo un vehículo de expresión y comunicación, sino que son también un medio de creación de la cultura. De ahí que el objeto del reconocimiento del bilingüismo en la Constitución no sea otro que reconocer sus derechos a los hablantes del castellano, lengua oficial de todos los españoles, sin restringir por ello la libertad de los que prefiere utilizar otras modalidades lingüísticas, sean éstas lenguas cooficiales o no. En otras palabras la consideración de la riqueza lingüística española como un patrimonio histórico y cultural común implica la necesaria convivencia armoniosa entre las mismas, sin poder verse coartados por ello, los principios constitucionales relacionados con el bilingüismo, como son la libertad, la igualdad o el principio de integración. Los ciudadanos tienen derecho a elegir, en libertad, la lengua en la que quieren expresarse. No son las lenguas quienes eligen a los hablantes, sino al revés. La liberta de elección de lengua, ya sea para ejercer el derecho de expresión, de manifestación, de educación u otros es básica y no cabe coacción alguna en su ejercicio.

Cuarta. La jurisprudencia aprobada en materia lingüística ha resultado insuficiente. Bien es cierto que tanto el Tribunal Supremo como el Tribunal Constitu- 
cional han afirmado que sólo del castellano se establece constitucionalmente un deber individualizado de conocimiento, y con él la presunción de que todos los españoles lo conocen (SSTC 82/86 y 84/86). Siguiendo con este razonamiento, los españoles tienen el derecho de usar el castellano como lengua vehicular, lo que implica poder acceder en dicha lengua a las normas que les vinculan y a otros documentos que sean de interés público. Sin embargo, la complejidad de la cuestión (STC 205/1990) no puede generar una laxitud en la defensa de los castellano-parlantes. La importancia simbólica y afectiva de una lengua cooficial no puede ser óbice para no cumplir con el mandato constitucional, que establece el español como lengua oficial, común a todos los españoles.

Quinta. La Ley de Transparencia estatal, al igual que las leyes de transparencia autonómicas establecen la creación de autoridades de transparencia independientes (Consejos de Transparencia) para velar por el cumplimiento de las obligaciones de los poderes públicas en materia de transparencia, así como para responder a las reclamaciones de los ciudadanos. A la luz de los datos analizados, no parece que las autoridades autonómicas de transparencia de Cataluña, Baleares y Galicia hayan mostrado su preocupación por el acceso a la información pública en una lengua comprensible para todos los españoles. Para garantizar dicho cumplimiento, es indispensable la cualificación de los titulares de dichas instituciones y su independencia. Sin una voluntad firme por hacer cumplir el mandato constitucional, la transparencia también se normalizará en las lenguas propias (como está ocurriendo) y no en la lengua oficial de todos los españoles.

Sexta. En nuestro país se ha velado por proteger y garantizar las demás lenguas cooficiales y/o minoritarias, hasta el punto de que, en algunos territorios se ha producido la paradoja de que la lengua cooficial ha desplazado, por muy diversos motivos, al castellano, es decir, a la lengua que reconoce el artículo 3.1 CE como la única lengua oficial para el conjunto de los españoles. Por consiguiente, la situación en que se encuentra la lengua común de todos los españoles aconseja la rápida adopción de medidas que garanticen su protección en el conjunto del territorio nacional y, de forma muy especial, en aquéllas zonas donde su uso y enseñanza se está viendo amenazado. Dichas medidas pueden suponer la aprobación de una Ley Orgánica de defensa y protección de la lengua castellana; la aprobación de una Ley de armonización en relación al uso del español en el conjunto del territorio nacional, o de otro tipo. El objeto de tales medidas debe ser reconocer la pluralidad lingüística de España y garantizar a todos los españoles el uso de sus lenguas y modalidades lingüísticas propias como un legado cultural e histórico que debe ser conservado, lo cual incluye la conservación, promoción, enseñanza y difusión del castellano y del patrimonio histórico y cultural común que se deriva del mismo. 


\section{BIBLIOGRAFÍA}

Libros y revistas

Aja, Eliseo, El Estado Autonómico. Federalismo y Hechos Diferenciales, Alianza, Madrid, 2007.

Alonso de Antonio, Ángel Luís, «La cuestión lingüística en la sentencia del Tribunal Constitucional sobre el Estatuto de Autonomía de Cataluña», UNED.

Teoría y Realidad Constitucional, núm. 27, 2011, pp. 449-460.

Diario de Sesiones del Congreso 41, 22 agosto 1978; N. , 67, 16 mayo 1978; N. ${ }^{\circ}$ 66, 12 mayo 1978

Diario de Sesiones del Senado, número 41, de 22 de agosto de 1978.

Díez-Picazo, L., y Gullón Ballesteros, A., Sistema de Derecho Civil, Tecnos, Madrid, 1981.

Fernandez LuQue, José Manuel, «El marco jurídico de la Transparencia en España», Revista de la Escuela Jacobea de Posgrado, N. ${ }^{\circ}$ 12, junio 2017, págs. 123-152 (p.131), disponible en http://www.jacobea.edu.mx/revista/numeros/numero12/6. Marco_legal_transparencia.\%20Jose_Manuel_Fernandez_Luque.pdf Fecha de consulta: 24 noviembre 2017

García de Enterría, Eduardo y Tomás Ramón Fernández, Curso de Derecho Administrativo II, Thomson-Civitas, Madrid, 2006.

Guichot Reina, Emilio (Coord.), Transparencia, acceso a la información pública y buen gobierno. Estudio de la Ley 19/2013, de 9 de diciembre, Tecnos, Madrid, 2014.

Guicнот, Emilio, «Reflexiones sobre la aplicación de la nueva normativa sobre transparencia», Revista Andaluza de Administración Pública, núm. 94, Sevilla, enero-abril (2016), pp. 89-106.

Gurrera Roig, Matilde, «El pluralismo lingüístico», Revista de Estudios Políticos, núm. 48, noviembre-diciembre 1985, pp. 221-232 (pp. 228-231).

LizCANo Álvarez, J., «Transparencia y corrupción. Un análisis desde la sociedad civil», en PAU i VALL (Coord.), La transparencia desde el Parlamento. XXI Jornadas de la Asociación Española de Letrados de Parlamentos, Aelpa-Tecnos, Madrid, 2015, pág. 80.

Moretón Toquero, M. Aranzazu, «Los límites del derecho de acceso a la información pública», en Revista Jurídica de Castilla y León, n. ${ }^{\circ}$ 33, mayo 2014, 24 pp., disponible en https://dialnet.unirioja.es/ejemplar/365711 Fecha de consulta: 5 febrero 2017

Muñoz Machado, S., «Dentro de los términos de la presente Constitución», en El Cronista del Estado Social y Democrático de Derecho, núm. 15, 2010, pág. 6.

Pla BoIx, Anna, La valoració del coneixement de la llengua pròpia i del dret propi de Catalunya en la provisió de places del personal al servei de l'Administració de justicia, Centro de Estudios Jurídicos, Generalitat Catalana, 2004, en http://justicia.gencat.cat/ web/.content/documents/arxius/doc_59956114_1.pdf Fecha: 6 febrero 2017. 
Rey Martínez, Fernando, «Quod omnes tangit ab omnibus cognitum esse debet: El derecho de acceso a la información pública como derecho fundamental», en Revista Jurídica de Castilla y León, n. ${ }^{\circ} 33$, mayo 2014, 19 pp., disponible en https://dialnet.unirioja.es/ejemplar/365711 Fecha de consulta: 5 febrero 2017

Rubio Llorente, Francisco, «Los deberes Constitucionales», Revista Española de Derecho Constitucional, Año 21. Núm. 62. Mayo-Agosto 2001, pp. 11-56.

SÁnchez Agesta, Luís, «La Lengua», en Óscar Alzaga (dir.). Revista de Derecho Privado. Comentarios a la Constitución española de 1978, Madrid, 1983, pp. 199 y ss.

Sanchez de Diego Y Fernández de La Riva, Manuel, Iurisprudentia Elegans: Revista de Derecho Político e Historia Constitucional, n. ${ }^{\circ} 1,2014$, pp. $30-55$ (p. 36), disponible en http://www.iurisprudentiaelegans.es/imagenes/numeros/Transparencia $\% 20 y \% 20$ acceso $\% 20 a \% 20$ la $\% 20$ informacion $\% 20$ desde $\% 20$ una $\% 20$ perspectiva\%20constitucional.pdf Fecha de consulta: 5 febrero 2017

VERNET I LlOBET, Jaume, «La perspectiva catalana en torno a la reforma constitucional de la estructura territorial del estado», Revista Española de la Función Consultiva, núm. 20, julio-diciembre (2013), págs. 79-109, p. 88, http://portales. gva.es/cjccv/pdfs/pub/refc-n20.pdf

\section{Normativa y Jurisprudencia}

Anteproyecto de Ley de Transparencia de la Comunidad Autónoma VASCA (en tramitación) en http://www.euskadi.eus/gobierno-vasco/-/plan_programa_proyecto/ley-de-transparencia-participacion-ciudadana-y-buen-gobierno-del-sector-publico-vasco/

LEY I/2016, de 18 de enero, de Transparencia y Buen Gobierno de la Comunidad Autónoma de Galicia, en http:/www.boe.es/boe/dias/2016/04/04/pdfs/ BOE-A-2016-3190.pdf

LEY 2/20I5, de 2 de abril, de la Generalitat, de Transparencia, Buen Gobierno y Participación Ciudadana de la Comunitat Valenciana, en https:/boe.es/buscar/ pdf/2015/BOE-A-2015-4547-consolidado.pdf

LEY 4/20I I, de 31 de marzo, de la Buena Administración y del Buen Gobierno de las Illes Balears, en https://boe.es/boe/dias/2011/04/30/pdfs/BOE-A-2011-7709. pdf

Ley Catalana i9/20 I4, de 29 de diciembre, de Transparencia, Acceso a la Información Pública y Buen Gobierno, en https://www.boe.es/diario_boe/txt.php?i$\mathrm{d}=$ BOE-A-2015-470

Ley Foral i I/20 I 2, de 21 de junio, de la Transparencia y del Gobierno Abierto, en http://www.boe.es/buscar/act.php?id=BOE-A-2012-9370

STC 82/86 EN HTTP://WWW.CONGRESO.ES/CONSTITUCION/FICHEROS/SENTENCIAS/ STC_082_I986.PDF 
STC 84/86 EN HTTP://WWW.CONGRESO.ES/CONSTITUCION/FICHEROS/SENTENCIAS/ STC_084_I986.PDF

STC 39/I986, de 31 de marzo, en http://www.congreso.es/constitucion/ficheros/ sentencias/stc_039_1986.pdf

STC I23/I988 EN HTTP://WWW.CONGRESO.ES/CONSTITUCION/FICHEROS/SENTENCIAS/STC_I 23_I988.PDF

STC 27/I98I, de 20 de julio, disponible en https:/guiasjuridicas.wolterskluwer.es/ Content/Documento.aspx? params = H4sIAAAAAAAEAMtMSbF1jTAAAUMTQxNztbLUouLM_DxbIwMDCwNzAwuQQGZapUt-ckhlQaptWmJOcSoAwrlbTjUAAAA = WKE\#I7

STC 205/I990 EN HTTP://HJ.TRIBUNALCONSTITUCIONAL.ES/IT/RESOLUCION/ SHOW/I 630

STC 337/I994 EN HTTP://WWW.CONGRESO.ES/CONSTITUCION/FICHEROS/SENTENCIAS/STC_337_I994.PDF

STS I668/20I5 DE 23 DE ABRIL DE 20I5, disponible en https://www.iberley.es/jurisprudencia/sentencia-administrativo-ts-sala-contencioso-sec-4-r ec-2548-2014-23-04-2015-46903261

Informes estadísticos

ASSOCIACIO DE SOCIOLINGÜISTES DE LLENGUA CATALANA, La situació sociolingüistica

ALS TERRITORIS DE PARLA CATALANA A L'INICI DEL SEGLE XXI. L'ALGUER, Andorra, Catalunya, Catalunya del Nord, la Franja, les Illes Balears i el País Valencià, 2007, en http://www.ub.edu/slc/socio/situacioactualcatala.pdf Fecha: 7 marzo 2017.

CONSELLO DA CULTURA GALEGA, «Número de hablantes», en http://consellodacultura.gal/cdsg/loia/ficha.php?idioma $=3$ \&seccion $=5$ Fecha de consulta: 4 febrero 2017.

EUSTAT, «Población de la C.A. de Euskadi por ámbitos territoriales, lengua materna y lengua hablada en casa», 2011, en http://www.eustat.eus/elementos/ ele0000400/ti_Poblacion_de_la_CA_de_Euskadi_por_ambitos_territoriales_lengua_materna_y_lengua_hablada_en_casa/tbl0000490_c.html\#axzz4XlBEmFrp

GENERALITAT VALENCIANA, Conocimiento y uso social del valenciano. Encuesta 2015, 2016, en file://C:/Users/Ainhoa/Downloads/encuesta\%20uso\%20 valenciano\%202015\%20espa\%C3\%B1ol.pdf y http://www.ceice.gva.es/web/ fondo-estadistico-documental

GOBIERNO DE NAVARRA, Mapa sociolongüístico de Navarra, 2011, en http:// www.euskarabidea.es/fitxategiak/dokumentuak/testuak/mapa-sociolinguistico-2011_informe-2.pdf Fecha de consulta: 7 de marzo de 2017. 
INSTITUTO GALEGO DE ESTADÍSTICA, «Coñecemento do Galego», 2013, https://www.ige.eu/estatico/estat.jsp? ruta $=$ html/gl/ecv/ECV_ResumoResultados_galego.html

Webs consultadas

CONGRESO DE LOS DIPUTADOS. Portal de la Constitución, en http://www. congreso.es/consti/constitucion/indice/sinopsis/sinopsis. jsp? art $=3 \&$ tipo $=2$

GOBIERNO DE ESPAÑA. PORTAL DE TRANSPARENCIA, en http://transparencia.gob.es/transparencia/transparencia_Home/index/Derecho-de-acceso-a-la-informacion-publica.html

GOBIERNO DE ESPAÑA. PORTAL DE TRANSPARENCIA. Categorías de la Información pública, http://transparencia.gob.es/transparencia/transparencia_Home/ index/categorias.html 4 febrero 2017.

GOBIERNO DE NAVARRA. I Plan Estratégico del Euskera (2016-2019), https:// www.navarra.es/home_es/Actualidad/Sala + de + prensa/Noticias/2017/01/25/ Aprobado + el $+\mathrm{I}+$ Plan + Estrategico + del + Euskera.htm

PARLAMENTO DE BALEARES. Web oficial en http://www.parlamentib.es/ Home/Default.aspx

PARLAMENTO DE CATALUÑA. Web oficial en http://www.parlament.cat/web/ index.html

PARLAMENTO DE GALICIA. Web oficial en http://www.parlamentodegalicia.es/ sitios/web/default.aspx

PARLAMENTO DE LA COMUNIDAD VALENCIANA. Web oficial en http:// www.cortsvalencianes.es/cs/Satellite/Layout/Page/1260974710668/Home.html?lang=es_ES

PARLAMENTO DE NAVARRA. Web oficial en http://www.parlamentodenavarra.es/

PARLAMENTO VASCO. Web oficial en http://www.legebiltzarra.eus/portal/es/ web/eusko-legebiltzarra

Title:

The protection of the Spanish language in the framework of the regional parliaments: The access in Spanish to the public information on their official websites. 


\section{Summary:}

I. Introduction: Approach of the Study Object. II. Legal Approach to the question. 2.1. The article 3 of the Constitution: background and meaning. 2.2. The constitutional principles of multilinguism. 2.3. The regional legal framework of bilingualism 2.4. Jurisprudence on the Spanish language. 2.5. The right to get access to law and public information in Spanish language. III. The praxis of the regional parliaments in the compliance with the article $3 \mathrm{CE}$, the art. $9 \mathrm{CE}$, and the art. 12 of the Act of Transparency. IV. Conclusions. V. Bibliography.:

\section{Resumen:}

La Constitución española establece en su artículo 3 que el castellano es la lengua oficial del Estado, al tiempo que reconoce la existencia de un plurilingüismo. Sin embargo, existen territorios donde los ciudadanos se enfrentan a una situación desigual a la hora de emplear el castellano como lengua vehicular. Esta situación es aún más grave si la desigualdad procede de los poderes públicos. El artículo es un estudio de caso del acceso a la información pública en lengua castellana, no en vano, junto al mandato del artículo $3 \mathrm{CE}$, el artículo 9 CE obliga a los poderes públicos a publicar las normas (lo que supone publicarlas también en español), al tiempo que el principio de publicidad se vio reforzado por la aprobación de la Ley 19/2013, de 9 de diciembre, de Transparencia, Acceso a la Información Pública y Buen Gobierno, y por las respectivas leyes de transparencia autonómicas, que regulan el acceso de los ciudadanos a la información pública. Dicho acceso a la documentación de carácter público debe hacerse, por ende, en la lengua oficial del país, así como en las lenguas cooficiales en sus respectivos territorios. Por ello, el artículo analiza el mayor o menor grado de acceso en lengua castellana a los documentos que publican en su página web los distintos parlamentos autonómicos, sean de naturaleza legal, política, económica o de otro tipo. En consecuencia, aquí se realiza un estudio de caso centrado en las seis Cámaras autonómicas con lenguas cooficiales, para verificar el grado de cumplimiento del artículo $3 \mathrm{CE}$, el artículo 9 CE, y el el artículo 12 de la Ley 19/2013, de 9 de diciembre, de transparencia, acceso a la información pública y buen gobierno. Son los siguientes: 1) El Parlamento Vasco (Eusko Legebiltzarra); 2) el Parlamento Navarro (Nafarroako Parlamentua); 3) el Parlamento Catalán (Parlament de Catalunya); 4) el Parlamento Valenciano (Corts Valencianes); 5) el Parlamento de Baleares (Parlament de les Illes Balears); y 6) el Parlamento Gallego (Parlamento de Galicia). El objetivo último de la presente investigación es abordar unas conclusiones que permitan fortalecer y hacer cumplir el mandato constitucional, así como permitir a los ciudadanos hacer uso de su lengua oficial. 


\begin{abstract}
:
The Spanish Constitution establishes in the article 3 that the Spanish is the official language of the State. It also enshrines the existence of mutilinguism in the country. However, there are some territories where citizens face inequalities when using Spanish as their mother tongue. This situation is even harder if the inequalities come from public powers. The article focuses on the citizens' access to public information in Spanish. In fact, not only the Spanish is the official language (art. $3 \mathrm{CE}$ ), but also the article 9 of the Constitution forces the public authorities to publish laws (which means also to publish them in Spanish), as well as the Act of Transparency, Access to Public Information and Good Government (Ley 19/2013) enables citizens to get access to public information (which means to access to the documents also in Spanish). Hence, the article analyses the level of public access in Spanish to the documents uploaded on the websites of the regional parliaments. Therefore, it is a case study focused on the six regional parliaments with more than one official language. They are the following ones: 1) The Basque Parliament (Eusko Legebiltzarra); 2) the Parliament of Navarra (Nafarroako Parlamentua); 3) the Parliament of Catalonia (Parlament de Catalunya); 4) the Valencian Parliament (Corts Valencianes); 5) the Parliament of the Balearic Islands (Parlament de les Illes Balears); and 6) the Galician Parliament (Parlamento de Galicia). It will study the level of compliance with the article 3 and 9 of the Constitution and the article 12 of the Act of Transparency, Access to Public Information and Good Government (Ley 19/2013). The aim of the article is to get to conclusions that enable the legislator to strengthen and force the compliance with the constitutional mandate, as well as to empower citizens to use the official language.
\end{abstract}

Palabras clave:

Lengua oficial, plurilingüismo, transparencia, información pública, multiparlamentarismo autonómico.:

Key words:

Official language, multilingualism, transparency, public information, regional parliaments: 